\title{
AVANCE DE LAS NUEVAS INVESTIGACIONES EN LA NECRÓPOLIS ROMANA DE CARMONA
}

\section{ADVANCEMENT OF NEW RESEARCH IN CARMONA ROMAN NECROPOLIS}

\author{
IGNACIO RODRÍGUEZ TEMIÑO* \\ ALEJANDRO JIMÉNEZ HERNÁNDEZ* \\ DANIEL GONZÁLEZ ACUÑA* \\ JOSÉ ILDEFONSO RUIZ CECILIA*
}

\begin{abstract}
Resumen: La Necrópolis Romana de Carmona fue excavada fundamentalmente a finales del siglo XIX. Desde entonces la significación cultural de los tipos de enterramientos que la caracterizan, cremaciones en cámaras hipogeas de carácter familiar, ha estado presente en los debates sobre la romanización del sur peninsular. Sin embargo, como presentamos en este artículo, el conocimiento que tenemos de este importante yacimiento es muy imperfecto ya que solo se ha transmitido una pequeña parte de los hallazgos realizados durante su excavación. La aportación de nuevos datos, hasta ahora inéditos, ayuda a cuestionar las hipótesis más difundidas sobre el carácter púnico de los habitantes de Carmona durante el siglo I d. C.

Palabras clave: Carmona Necrópolis Romana Romanización Punicidad Tumbas Hipogeas
\end{abstract}

\section{INTRODUCCIÓN}

Los terrenos donde se emplazó la Necrópolis Romana de Carmona fueron objeto de excavaciones dispersas durante los años centrales del siglo XIX (figura 1). Estas estuvieron dirigidas por eruditos locales, en ocasiones acompañados por individuos pertenecientes a las academias sevillanas, otros cuerpos literarios

\footnotetext{
* Conjunto Arqueológico de Carmona. http://www.juntadeandalucia.es/cultura/museos/CAC // necropoliscarmona.ccul@juntadeandalucia.es
}

\begin{abstract}
The Necrópolis Romana de Carmona was excavated mainly in the late nineteenth century. Since then the cultural significance of the burial typology that characterizes this site -familiar cremation hypogean chambers- has been under the debate of the Romanization of the southern Spain. However, as presented in this paper, the knowledge we have of this important site is very imperfect and has been transmitted only a small part of the findings made during the excavations. Unpublished new data helps to challenge the most widespread assumptions about the Punic nature of the inhabitants of Carmona during the first century AD.
\end{abstract}

Key words: Carmona Roman Necropolis Romanization Punicity Hipogean Burials

e, incluso, la Universidad hispalense. Las indagaciones en la necrópolis no adquirieron carácter sistemático hasta la asociación de Juan Fernández López, farmacéutico y coleccionista local, y George E. Bonsor, pintor tardorromántico de origen anglofrancés, en la década de los ochenta de esa centuria (Rada y Delgado 1885: 81 ss., Maier Allende 1999: 40-72 y Gómez Díaz 2001: 18-37). Ambos adquirieron en régimen de proindiviso los terrenos donde conocían la existencia de las tumbas: los campos de los Olivos, las Canteras, los Túmulos y, finalmente, la parte donde se encuentra la tumba de Servilia de la denominada cantera Mayor 


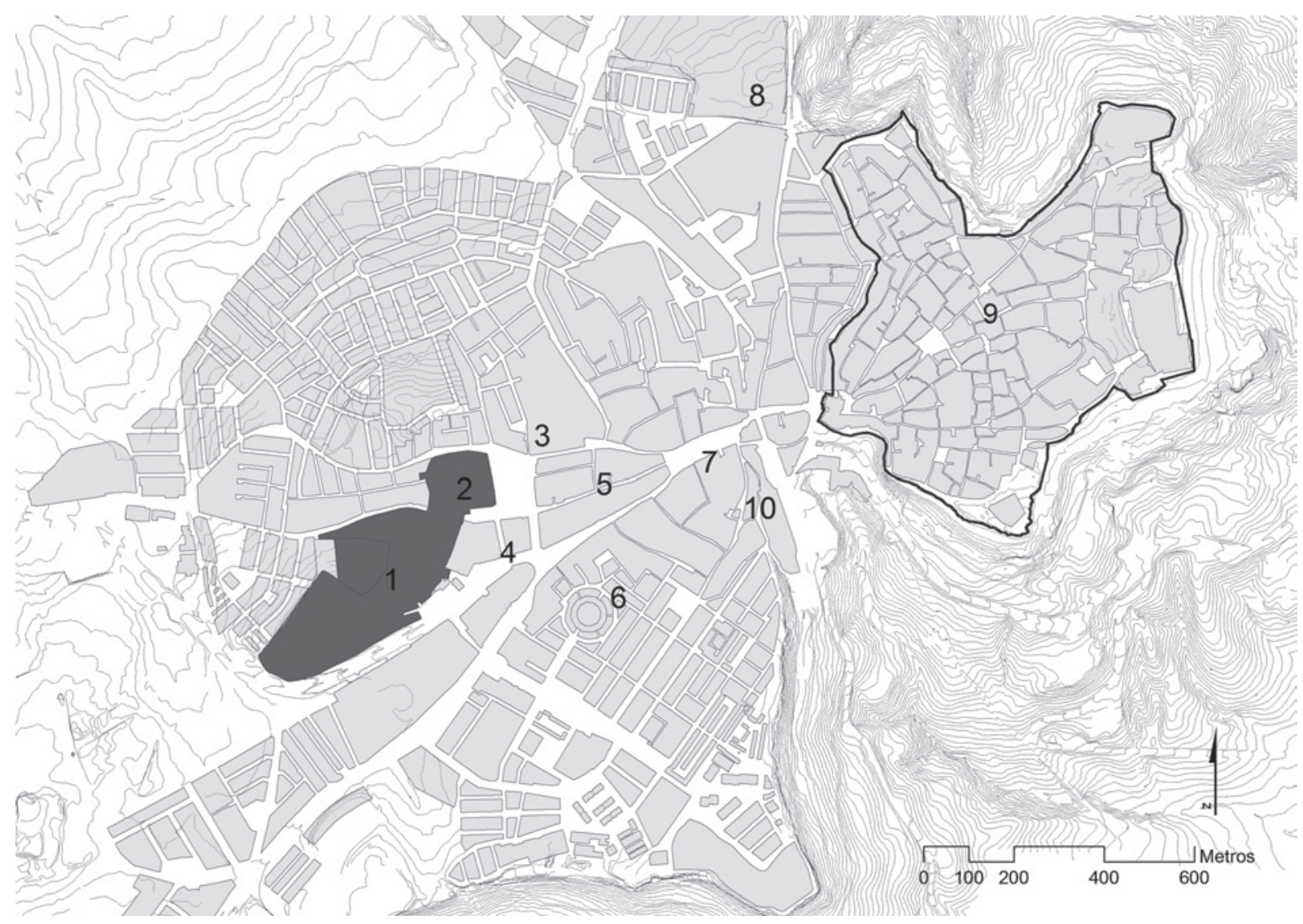

Figura 1. Plano del CAC y sus alrededores con indicación de los topónimos mencionados en el texto: 1. Finca integrada en el CAC donde se encuentra el núcleo principal de la necrópolis romana de Carmona; 2. Finca integrada en el CAC donde se halla el anfiteatro; 3. Zona donde apareció la denominada tumba de Nemesio; 4. Solar frontero a la Corredera donde se realizan las excavaciones de nuevas tumbas por parte del equipo de arqueología municipal; 5. Calle de En medio donde aparecieron tumbas; 6. Sector de La Calderilla donde se excavaron tumbas a finales del siglo XIX: 7. Paseo del Estatuto donde ha aparecido un mausoleo conservado in situ; 8. Sector de la puerta norte de la ciudad donde se excavaron diversas tumbas en el cortinal Alto; 9. Recinto de Carmo.

o de Delia. Como es bien conocido, entre 1883 y 1905 llevaron a cabo excavaciones en ellos, de manera intermitente.

Estas fueron supervisadas sobre el terreno, de manera constante, por Juan Fernández López, acompañado en ocasiones por algún otro miembro de la Sociedad Arqueológica de Carmona. Fernández López llevó un diario donde anotó los hallazgos acaecidos y las incidencias de todo tipo que ocurrieron a lo largo de tantos años de trabajo ${ }^{1}$. George E. Bonsor, por su parte, se

1. El manuscrito del diario de excavaciones se conserva en el archivo del Conjunto Arqueológico de Carmona con la signatura ACAC III.1.3. caja 1, libro 3 [Juan Fernández López] «Diario de excavaciones 1884-1905». Este documento es prácticamente desconocido por la investigación ya que Juan Fernández apenas publicó nada dedicó al levantamiento de las principales estructuras exhumadas. Pero sobre todo fue el gran divulgador de la necrópolis de Carmona, labor que compaginaba con sus propias indagaciones fuera de ese ámbito (Bonsor 1897, 1898 y 1899a).

El proceso de excavación sistemática de los terrenos adquiridos para esta finalidad culminó con el desentierro de un amplio número de complejos funerarios de época romana ${ }^{2}$, muchos de los cuales estaban

de sus excavaciones (Fernández López 1887 y Gómez Muñiz et alii 1887). Esperamos poder publicar su edición en un futuro próximo.

2. El término «complejo funerario» es usado aquí como sinónimo de tumba. Con ello queremos destacar que las tumbas están compuestas por diversas estructuras articuladas entre sí, pero conservando cada una de ellas una funcionalidad específica dentro del global destino funerario. 
expoliados (Bonsor 1931: 11). La mayor parte de ellas responde a lo que podría denominarse como «tipo común», definido por tratarse de cámaras subterráneas, de planta de tendencia rectangular o cuadrangular, encajadas en el macizo calcarenítico terciario característico de la formación de los Alcores. A ellas se accede por un pozo vertical con huecos practicados en las paredes, o bien mediante escaleras realizadas con frecuencia como ampliación de los pozos originales. Las cámaras suelen disponer de nichos para alojar urnas donde se conservaban los restos de la cremación de los cuerpos, así como de un banco que perimetra tres -o más raramente cuatro- de sus lados, salvo en el que se encuentra la puerta que comunica pozo y cámara. Este tipo de tumba se ha convertido en la seña de identidad de la necrópolis occidental de Carmona. Junto a ellas se encuentran otras que pueden considerarse variantes de este tipo simple añadiendo más cámaras; o bien modelos distintos del anterior, que han sido calificadas como «tipos singulares» (Columbario-Triclinio, triclinio del Olivo, tumbas del Elefante, de Servilia, de las Cuatro Columnas, mausoleo Circular o las tumbas de Prepusa y Postumio, por citar algunos ejemplos).

El número exacto de complejos funerarios de época romana excavados es objeto de no poca imprecisión, pero siendo esta discusión de interés ${ }^{3}$, ahora importa señalar que solo se ha publicado una mínima parte del monto de tumbas conocidas, centrada en aquellas que presentan cierta singularidad, pretiriendo para un futuro incierto analizar el resto. No obstante lo cual, la necrópolis occidental de Carmona ha participado en uno de los debates más interesantes referidos a la Antigüedad, el relativo al proceso que conocemos con el nombre de romanización. Con respecto a la necrópolis de Carmona, la cuestión ha pivotado sobre el valor otorgado al significado e importancia de manifestaciones (como rituales, formas hipogeas de las tumbas y

3. En efecto, la fijación de este número ha sido objeto de algunos intentos de computación (Maier Allende 1999: 40 ss y Gómez Díaz 2001: 18 ss.), sin que pueda llegarse a definir con exactitud. El propio Bonsor no contribuyó a clarificar el monto de las excavadas, a pesar del inventario realizado de ellas y su anotación en una plano general de las excavaciones. A finales del siglo XIX reconocía haber excavado casi trescientas (Bonsor 1899b: 62), pero treinta años más tarde, ochocientas (Bonsor 1931: 4). Cuesta trabajo pensar que durante el primer tercio del siglo $\mathrm{XX}$, cuando apenas se registra actividad arqueológica alguna en la Necrópolis romana ni en sus alrededores, casi se triplicase el número de tumbas localizadas y excavadas. Tampoco avalan la cifra de ochocientas ni el documento manuscrito del diario de excavaciones de Juan Fernández López ni la planimetría general de las excavaciones, guardada en el Fondo Bonsor del Archivo General de Andalucía (Cruces Blanco [dir.] 1991). El ordinal más alto reconocible en el citado plano es el 470. vasos cerámicos que acompañan a los difuntos), cuya progenie prerromana no se ha discutido, junto a los elementos considerados como plenamente romanos.

Esta cuestión ha estado presente desde las primeras publicaciones sobre la necrópolis carmonense, pero ha sido en los últimos años cuando se ha agudizado el debate. Para entender las novedades aportadas por las últimas investigaciones que viene realizando el equipo del Conjunto Arqueológico de Carmona, institución heredera de la antigua Necrópolis Romana de Carmona (Gil de los Reyes y Gómez Saucedo 2001; Aspas Jiménez y Tocino Rentero 2004 y Rodríguez Temiño 2010), conviene hacer un repaso del proceso de publicación de los complejos funerarios de esta necrópolis, así como de las valoraciones sobre la impronta púnica de muchos de los rasgos que la caracterizan.

Antes de pasar al análisis anunciado, debemos cerrar esta introducción con una consideración más sobre la Necrópolis Romana de Carmona. Bonsor y Fernández López adecuaron los terrenos donde habían realizado las excavaciones para su presentación, dando nacimiento a la Necrópolis Romana de Carmona (Maier Allende 1999: 70 ss.). Para favorecer su visita pública siguieron un modelo de presentación en forma de jardín ecléctico donde los complejos sepulcrales romanos se insertaban entre isletas dedicadas a la plantación de vegetación autóctona (Gómez Díaz 2006) (figura 2). Tales isletas se realizaron amontonando la tierra extraída de las tumbas en torno a las trincheras de excavación, a modo de enormes jardineras artificiales. Esta adecuación alteró, por lo menos, el aspecto con que los complejos salieron a la luz y los vestigios - pocos o muchos- del paleopaisaje funerario de este sector de la necrópolis occidental de Carmona. Podría decirse que la creación de la institución Necrópolis Romana de Carmona ocultó, a raíz de su musealización, parte de los restos de este sector de la necrópolis romana de la ciudad.

\section{LA NECRÓPOLIS ROMANA DE CARMONA Y EL DEBATE SOBRE LA ROMANIZACIÓN}

Juan de Dios de la Rada y Delgado, tras haber asistido a la solemne inauguración de la Necrópolis en 1885 en representación de las reales academias de la Historia y de Bellas Artes, publicó ese mismo año la primera guía del yacimiento, en base a la documentación entregada por Fernández López y Bonsor (Rada y Delgado 1885).

De la Rada (1885: 138 ss.) supuso una filiación egipcia y asiática, en general, para las tumbas, concordante 


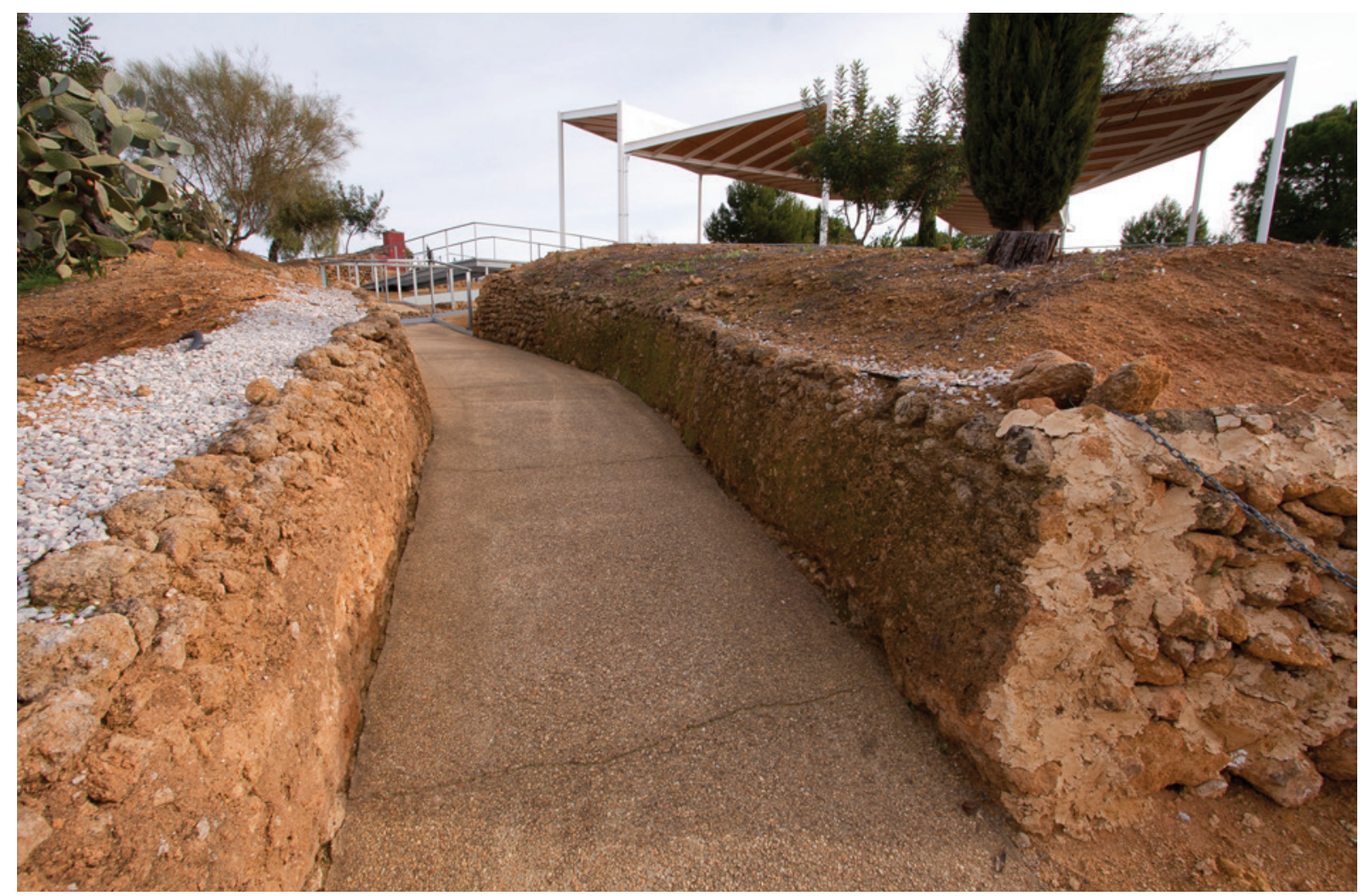

Figura 2. Parterres artificiales (foto CAC).

con la progenie de los habitantes de la antigua Carmo, si bien localiza en el mundo etrusco el principal foco de influencia en cuanto a la tipología de los sepulcros hipogeos. Filiación aceptada por la erudición local (Fernández López 1886), pero rechazada de manera tajante por Sales y Ferré (1887: 101 s.), para quien la necrópolis es romana sin más.

A Manuel Fernández López, miembro de la Sociedad Arqueológica de Carmona, como Bonsor y su hermano Juan, se le deben dos obras con referencias a la necrópolis occidental de Carmona (Fernández López 1886 y 1899). En la primera, de carácter más general, da información de utilidad sobre las tumbas, con especial dedicación a las más vistosas. La segunda repite las mismas ideas, aunque se trata de una monografía sobre la tumba del Elefante.

Ignoramos por qué Juan Fernández López, que llevó el diario de excavaciones, nunca publicó nada sobre ellas, más allá de las crónicas escritas en las actas de la Sociedad Arqueológica de Carmona. El principal difusor de la necrópolis fue, como ya se ha mencionado, George E. Bonsor. Con sus dibujos de los complejos funerarios más relevantes y algunas notas extraídas del «Diario de excavaciones» de Juan Fernández López, compuso una visión general de la necrópolis, dentro de un trabajo sobre la comarca de los Alcores, en la provincia de Sevilla (Bonsor 1899b: 62 ss.). Conviene advertir que en él adjudicaba una filiación fenicia a las tumbas familiares de Carmona, aunque estuviesen datadas en época de los primeros emperadores.

Con carácter póstumo apareció otro, esta vez monográfico sobre la necrópolis, publicado por la Hispanic Society of America (Bonsor 1931). No obstante, en ninguno de los dos ofreció toda la documentación disponible sobre las excavaciones que se habían llevado a cabo. Limitó sus descripciones a las tumbas de las que había sacado la planta, conjunto aumentado con una selección de los principales croquis elaborados por Fernández López; en total poco más de una veintena de ejemplares. El resto ha quedado inédito.

Ya en el siglo XX, R. Thouvenot (1940: 569) destaca los rituales totalmente romanizados de la necrópolis puntualizando, no obstante, que los pozos de acceso a las cámaras funerarias tienen resabios cartagineses. Este rasgo, en su opinión, pondría de manifiesto que la intensa romanización de la Bética fue compatible con la subsistencia de costumbres provinciales. 
En el volumen dedicado a Carmona del monumental Catálogo Arqueológico y Artístico de Sevilla y su provincia, encargado por la Diputación provincial de Sevilla (Hernández, Sancho y Collantes de Terán 1943), se presta especial atención a este singular enclave, para entonces declarado ya monumento histórico-artístico de carácter nacional. Sin embargo, aunque se hacen levantamientos nuevos, por ejemplo de la tumba de Servilia, Francisco Collantes de Terán resuelve la descripción de todos los complejos funerarios volviendo a generalizar sobre los comunes y resaltando aquellos especiales. Este autor puntualizó la semblanza de las tumbas carmonenses con los hipogeos fenicios, pero dentro de unos rituales puramente romanos (Hernández, Sancho y Collantes de Terán 1943: 96).

Como directora del Museo Arqueológico de Sevilla desde 1959, Concepción Fernández-Chicarro y de Dios, también lo fue del museo arqueológico de la $\mathrm{Ne}$ crópolis Romana de Carmona, que dependía del provincial de iure desde 1941. Con ella la Necrópolis vive un momento importante de actividad y reforma, como no lo había hecho desde 1905 . No es este el momento para tributarle justo reconocimiento a su labor, pero debe señalarse que consiguió la adquisición para el Estado de la finca en que se encontraba el anfiteatro, que lo excavó junto a un amplio conjunto de tumbas en ese sector (Fernández-Chicarro 1970 y 1978). A ella también se debe la última guía editada del yacimiento y del museo (Fernández-Chicarro 1969). Como todos los trabajos precedentes, dedica unas páginas a la semblanza general de las tumbas de cámara y pozo (que hemos denominado de tipo común) centrando su principal atención en las que la bibliografía anterior ya había destacado.

Concepción Fernández-Chicarro parece más renuente a la hora de valorar los posibles precedentes de la necrópolis. En su guía sobre la Necrópolis (Fernández-Chicarro 1969) apenas apunta alguna semejanza púnica para justificar la presencia de la escultura de un elefante en la tumba homónima, pero elude mayores pronunciamientos. Asume que se trata de una sociedad perfectamente romanizada. La cerámica a bandas, habitual en la necrópolis como parte del ajuar o sirviendo de urna funeraria, la considera como una pervivencia de la tradición indígena (Fernández-Chicarro 1970 y 1978), tal y como se hacía por la teoría clásica sobre la romanización, reforzada en España por la imagen del proceso transmitida por las Fontes Hispania Antiquae.

En 1976 se publicó la tesis doctoral de Manuel Bendala Galán, por entonces profesor de la Universidad de Sevilla, dedicada al sector de la necrópolis occidental conservada en la Necrópolis Romana de Carmona. Si bien trata el tipo común de tumbas, del que extrae las principales conclusiones sobre la significación cultural de esta necrópolis en el proceso de romanización, su esfuerzo analítico y descriptivo se centró en las tumbas conocidas por su singularidad, sobre todo en las del Elefante y Servilia (Bendala Galán 1976).

Desde la introducción advierte del cambio de orientación en lo referido a la significación de esa filiación semítica de las tumbas de la necrópolis carmonense: la huella de lo púnico en Carmona se habría mantenido vigente, incluso bajo la arrolladora pisada romana (Bendala Galán 1976: 19).

Como quiera que el desarrollo de esta idea no se agota en esa obra, sino que ha sido una de las constantes en buena parte de su producción científica, extendida además al plano de lo urbano, para procurar una explicación suficientemente abarcadora del enriquecimiento que ha ido adquiriendo con el tiempo, usaremos un amplio repertorio de sus publicaciones posteriores, aunque nos limitemos a los comentarios sobre la necrópolis de Carmona.

Bendala parte del cuestionamiento del término romanización para explicar el cambio operado en la península ibérica por parte de Roma, a partir de la Segunda Guerra Púnica. Este proceso no fue tan avasallador como venía siendo expuesto desde las primeras obras dedicadas al Imperio en el siglo XIX; tampoco gozó de los mismos mecanismos en todo el orbe romano, ni siquiera a escala de la península ibérica. Y, desde luego, no perpetró la aniquilación de las culturas prerromanas; ni resulta históricamente adecuado considerar las manifestaciones culturales indígenas, que perduraron bajo dominio romano, como meros residuos debidos a un grado de romanización deficiente.

Desde esta óptica aborda el encuentro cultural producido durante la República y los primeros años del Imperio entre las sociedades prerromanas y los dominadores, sobre todo para el ámbito de la Bética. En su opinión, el éxito de Roma en esta provincia se debe a que ya, a lo largo del periodo de sometimiento a Cartago, la Bética había entrado en una dinámica similar a la romana: su helenización. Impulso acelerado bajo la familia Barca. Roma y los príncipes bárquidas estaban imbuidos de una misma influencia helenística, lo que provocó una profunda sintonía entre ambas. Podría decirse que Hispania acompañó a Roma en su proceso de helenización, hecho que favoreció la aceptación del nuevo dominio romano.

Amén de este papel de bisagra entre lo púnico y lo romano jugado por el helenismo, también debe traerse 
a colación la inexperiencia colonizadora de Roma en esas fechas (de hecho, hasta César no comenzó una auténtica romanización cultural), así como que prefirió alterar lo mínimo posible el estado de cosas que encontró, siempre que no se opusiera a sus pretensiones. Este cúmulo de circunstancias propició la pervivencia de tradiciones culturales nacidas en la etapa anterior, de las que el registro arqueológico da suficientes muestras. La romanización debe entenderse como el estudio y análisis de las diferencias que sustentan las culturas provinciales.

Carmona vendría a ser un ejemplo de ese proceso. La ciudad habría sido transformada por los cartagineses para potenciar su función como bastión, añadiendo un baluarte defensivo en el flanco occidental -el más expuesto- origen de la Puerta de Sevilla. Así lo confirmaría un estudio monográfico sobre el monumento ( $\mathrm{Ji}$ ménez Martín 1989).

La otra pieza clave para aquilatar este discurso era lógicamente la necrópolis. Los rituales funerarios tienen un alto valor cultural, como proyección de la sociedad frente a propios y ajenos. Su forma más característica de enterramiento, la que hemos denominado como tipo común, calificada por Bendala como neopúnica para definir su carácter, sería la perduración de un modelo tradicional del mundo púnico, extendido por el norte de África y las islas mediterráneas, de larga duración.

Otra serie de peculiaridades observables, según este autor, en los ritos funerarios constatados en la necrópolis occidental de Carmona, apoyaría los ascendentes púnicos. Por ejemplo, el paisaje funerario. Pese a haberse perdido mucho de la apariencia exterior de las tumbas, barrunta su escasa proyección sobre rasante, configurándose una necrópolis con una disposición semejante a la propia de cementerios fenicio-púnicos, como el de Puig des Molins. Tampoco se perciben ordenaciones en calles funerarias, tan características de las necrópolis romanas, detectadas por ejemplo en Córdoba, Mérida y otras ciudades romanas. Igualmente no constata en Carmona la presencia de tumbas en forma de altar, asociadas en otras ciudades de la Bética a una temprana corriente de romanización de los ambientes funerarios.

Más allá de lo meramente formal, Bendala advierte que también el ritual tiene evidentes connotaciones púnicas. Como en las tumbas hipogeas de estos, el pozo de acceso a las cámaras carmonense era cegado tras los enterramientos ${ }^{4}$; tampoco es habitual en esta necrópolis

4. Este hecho había pasado desapercibido a Fernández López y Bonsor. De la Rada y Delgado (1885: 95) da cuenta del mismo en el la presencia de monedas en los enterramientos, como sí ocurre en la mayoría de los romanos. Por último, la ausencia de cerámicas romanas del tipo de la terra sigillata denotaría una especial reluctancia al empleo de estas especies foráneas en cultos privados, como los funerarios.

En medio de estas tumbas, que modelan un ambiente cargado de resonancias púnicas, la de Servilia, cuyo patrón resulta absolutamente distinto, se explica por pertenecer a la aristocracia funcionarial romana.

Esta raigambre púnica de las tumbas de la necrópolis occidental de Carmona no debería entenderse como una suerte de reminiscencia del pasado, sino que supondría un destacado componente étnico. Bendala asume que la identidad étnica implica el mantenimiento activo de fronteras en el proceso de interacción social, más allá del mero reflejo pasivo de normas culturales. Mantener el ambiente púnico en el mundo funerario ha de entenderse como una reivindicación identitaria, como no-romanos, de los habitantes de Carmona en las fechas que dura ese espacio sepulcral (desde el siglo I a. C. a fines del I d. C.), lo que no obsta para su romanización e integración en el Imperio.

Se daría una doble autoafirmación: de un lado, como carmonenses, manifestada en la perduración de los ritos funerarios; de otro, como miembros del Imperio, en el ámbito de la vida pública.

Pero estas pervivencias no fueron inamovibles, sino que en la misma necrópolis advierte claros indicios de evolución, con ingredientes de una romanización que fue impregnando esos ámbitos donde se había hecho fuerte la tradición. Por ejemplo, resultaría una pulsión derivada de actitudes culturales romanas la dignificación, a través de la arquitectura, de los complejos funerarios, como se percibe en el ámbito cívico. En virtud de ello pueden explicarse algunos cambios en la construcción y la configuración de las tradicionales cámaras hipogeas carmonenses, como el paso de la cueva excavada en la roca a la cueva artificial. Transformación conseguida mediante el empleo de bóvedas de cañón construidas con dovelas. Este fenómeno de dignificación mediante el empleo de elementos arquitectónicos en las cámaras hipogeas, manifestado en los mausoleos circulares, sería una expresión de prestigio, característica de ambientes más romanizados. Como lo fue también la simulación de un atrio en el interior

caso de la tumba 106, según la numeración de sus excavadores. Posteriormente fue confirmado por María Belén Deamos (1983: 217) en la excavación de la tumba $n^{\circ} 53$, del conjunto excavado en el entorno del anfiteatro. 
de la cámara, caso de la tumba de las Cuatro Columnas. La ritualidad funeraria cambió en este mismo sentido. Del cegamiento ritual del pozo, tras cada utilización de la cámara, se pasó al cierre por grandes sillares, que sellaban su boca de acceso; como se observa, por ejemplo, en el denominado mausoleo Cuadrangular. Por último, también se daría cierta ordenación en las tumbas más romanizadas, los mausoleos circulares, en el campo de las Canteras, una de las zonas más alejadas de la necrópolis respecto de la ciudad (Bendala Galán 1976, 1981, 1982, 1991, 2001, 2002 y 2005, como muestra de un amplísima bibliografía sobre esta cuestión).

La interpretación sintetizada aquí ha sido hegemónica durante casi veinte años. Ni siquiera se ha visto afectada porque las excavaciones de finales de los setenta y comienzos de los ochenta ampliaran el registro tipológico de las tumbas conocidas. En efecto, las excavaciones Fernández-Chicarro y, más adelante, de María Belén Deamos y su equipo se centraron sobre todo en la parcela en la que se encuentra en anfiteatro, para saltar, más adelante, a los túmulos prerromanos situados en el campo de las Canteras ${ }^{5}$. Se excavaron casi un centenar de tumbas de variada tipología que, si bien no eran desconocidas pues ejemplares análogos habían sido descubiertos por Fernández López y los miembros de la Sociedad Arqueológica de Carmona, no tuvieron el eco necesario en las publicaciones posteriores. Aparte de tumbas de pozo y cámara, aparecieron cremaciones recogidas en urnas cerámicas, diversos tipos de busta en fosa cubiertas por tegulae o roscas de ladrillos del tipo de las cupae, así como inhumaciones en fosa, en ocasiones con forro interior de ladrillos y cubiertas de tegulae. Todo ello datado entre los siglos II y I a. C. y siglo II d. C. Desgraciadamente solo un número corto de estas tumbas ha sido publicado (Belén Deamos 1982, 1983; Belén, Gil et alii 1985, 1987 y Belén, Lineros et alii 1987).

Debe destacarse que también se intervino en la necrópolis situada al exterior de la puerta norte de Carmona, ubicada en la Sedía, en el paraje conocido como cortinal Alto. En este sector, la mayor parte de los enterramientos era similar a los excavados en el anfiteatro, aunque presentaban determinadas distinciones: eran frecuentes las monedas y también los canales para la realización de las libaciones. En algún caso, una perforación circular practicada en una de las tejas de la cubierta jugaba la misma función. Normalmente en el

5. Agradecemos a María Belén las puntualizaciones hechas personalmente acerca de sus excavaciones. exterior de la tumba, se encontraban vasos de ofrendas. Todas estas tumbas solían contener una o dos monedas y ungüentarios. La mayoría de las monedas pertenecen a los emperadores Adriano o Antonio Pío (Belén, Gil et alii 1985: $57 \mathrm{~s}$. ).

Para María Belén y su equipo, la diferencia entre los dos sectores es relevante. La necrópolis oeste estuvo ocupada en época republicana. Durante ese periodo, junto a los enterramientos indígenas de cremación (Belén 1982), se documentan también tumbas de inhumación con ajuares que hacen pensar en núcleos de personas venidas de fuera. En su momento más característico, dentro del siglo I d. C., son dominantes las cámaras hipogeas de carácter familiar, que continúan apegadas a tradiciones púnicas.

Belén y su equipo piensan que desde el siglo I, y durante el siglo II, vienen a Carmona elementos foráneos, de origen oriental, que se entierran sobre todo en un área concreta de la necrópolis occidental, situada junto al anfiteatro, no frecuentada por la población local en esos momentos, conservando los rituales de procedencia (Belén, Gil et alii 1985: 59).

El fuerte carácter púnico otorgado a Carmona, a través de los estudios de la necrópolis occidental y de la Puerta de Sevilla, durante la década de los setenta, comenzó a cuestionarse a mediados de los noventa. P. Moret (1996: 540 s.) dudaba de las fechas atribuidas al bastión de la Puerta de Sevilla debido al imperfecto conocimiento de las excavaciones llevadas a cabo en él (cuya única reseña se encuentra en Jiménez Martín 1989: 167 ss.) y, más adelante, Th. Schattner (2005) aboga de manera contundente contra la datación púnica de la obra, que considera augustea. Despunificación que también se ha extendido a la necrópolis occidental. Antonio Caballos Rufino (2001 y 2007) y Géza Alföldy (2001) han reivindicado la plena romanidad de la misma, sin que para ello obste la semblanza púnica de la tipología de las tumbas, al entender que tales peculiaridades son perfectamente normales en los comportamientos culturales provinciales. Según estos autores, para hablar de punicidad deberían darse otras constantes de orden social, con reflejo en rituales y cultura material, totalmente ausentes en Carmona.

Como fruto de las actividades arqueológicas urbanas, también se han excavado algunos complejos funerarios dentro de la necrópolis oeste, en el entorno del recinto del Conjunto Arqueológico de Carmona (Anglada y Conlin 2003a y 2003b). Mientras se redacta este trabajo, se están llevando a cabo unas excavaciones preventivas, dirigidas por Juan Manuel Román Rodríguez, que han sacado a la luz tres complejos 
funerarios hipogeos compuestos por cámara con banco y nichos y pozo de acceso, así como dos inhumaciones y un ustrinum (El Correo de Andalucía de 20 de agosto de 2011) ${ }^{6}$, en un solar frontero a la Corredera.

Desiderio Vaquerizo ha tratado las necrópolis de Carmona en diversas ocasiones, dentro de estudios acerca de la impronta púnica en los cultos funerarios romanos en la Bética o de trabajos, de ámbito más general, sobre las necrópolis urbanas de esta provincia (Vaquerizo Gil 2006: 321-325 y 2010: 238 ss.). En ambas ocasiones, este autor ha realizado un completo análisis sobre las diversas opiniones vertidas acerca de la profundidad de la impronta púnica y su significado en la necrópolis occidental, añadiendo comentarios y matizando algunas de ideas expuestas tanto por Bendala como por Caballos y Alföldy. Sin embargo, aunque la falta de datos concluyentes parece aconsejarle prudencia y la impronta púnica en la Bética resulte incuestionable, en términos generales se muestra muy escéptico sobre su perduración al final de la República y comienzos del Imperio, justamente cuando la mayor parte de las ciudades iniciaban proyectos de monumentalización y las élites urbanas ostentaban su romanidad (Vaquerizo Gil 2006: 318 s. y 347 ss.).

Finalmente, en su estudio sobre algunas necrópolis béticas con fuerte influjo prerromano, Alicia Jiménez (2008) toma las tumbas de cámara de la necrópolis occidental de Carmona como referencia de necrópolis donde la impronta púnica se manifiesta de manera notable durante época romana. Estos rasgos, que no duda en denominarlos étnicos en línea con lo expuesto por Bendala, serían manifestación del hibridismo cultural característico de la romanización de sociedades donde las connotaciones púnicas se entenderían como una activación identitaria, frente a la colonización romana.

Sin duda esta revisión de la historia de las excavaciones en las necrópolis romanas de Carmona y su participación en el debate sobre la romanización es incompleta. No obstante, resulta suficiente para evidenciar un aspecto clave de la forma en que ha sido presentada: muchas de las idées reçues que con mayor insistencia se han reproducido a lo largo de estos años están construidas sobre datos e informaciones manifiestamente parciales. Esta parcialidad no proviene solo por la existencia aún de muchos complejos

6. Agradecemos a Juan Manuel Román Rodríguez, director de la intervención, y a Ricardo Lineros Romero, director del Museo de Historia Local de Carmona, que nos permitan usar los datos que, hasta el momento, ha arrojado esta intervención. No obstante, para una información más completa remitimos a su publicación o, eventualmente, a los informes sobre esta excavación. funerarios no descubiertos, sino sobre todo porque únicamente ha trascendido una mínima parte de lo ya descubierto.

Sin desdeñar la importancia capital que ofrecerán nuevos datos registrados con metodología arqueológica que, sin duda, ayudarán a completar la información lacunaria que poseemos, debemos señalar que la necrópolis occidental de Carmona no está agotada, ni de lejos. La mayor parte de los complejos funerarios sacados a la luz por Fernández López y Bonsor, a finales del siglo XIX, están aún virtualmente inéditos. Por ello, una de las principales labores realizadas por el equipo actual del Conjunto Arqueológico de Carmona ha sido retomar la investigación historiográfica y arqueológica de los bienes que custodia. Se ha emprendido un proyecto de investigación sobre el anfiteatro y los complejos funerarios de este coemeterium, así como de la documentación histórica de sus excavaciones y de la Sociedad Arqueológica de Carmona. No es ahora el momento de extenderse sobre los objetivos de este proyecto, que está viendo ya sus primeros frutos (Jiménez, López y Rodríguez 2010; Ruiz Cecilia et alii 2011) y es de acceso público en internet ${ }^{7}$. Como plataforma para sostener la investigación se ha escaneado todo el archivo histórico del CAC, incluidas las referencias bibliográficas aparecidas tras los diversos episodios de excavaciones que ha experimentado la necrópolis y el anfiteatro y la planimetría ráster histórica que refleja tales excavaciones y los fondos fotográficos. También se ha dotado al yacimiento de una infraestructura topográfica sobre la que se han apoyado todos los procesos de georreferenciación y el levantamiento de las 352 entidades arqueológicas, entre complejos funerarios, estructuras superficiales y el anfiteatro, que componen el yacimiento por sistemas de registro tridimensional: escáner $3 \mathrm{~d}$, topografía de detalle y fotogrametría terrestre y aérea.

Como resultado se ha obtenido un Modelo Digital Terrestre (MDT) compuesto por una malla realizada por correlación fotogramétrica, a lo que se suma el escaneado $3 \mathrm{~d}$ de todas las estructuras arqueológicas antes mencionadas.

Por último, se ha comenzado el inventario de los bienes muebles procedentes de las antiguas excavaciones y, en la medida de lo posible, se intenta establecer asociaciones entre complejos funerarios y los ajuares conservados tanto en el Conjunto Arqueológico de Carmona como en el Museo Arqueológico de Sevilla.

7. http://www.juntadeandalucia.es/cultura/museos/CAC 


\section{NOVEDADES EN LA INVESTIGACIÓN DE LA NECRÓPOLIS ROMANA DE CARMONA}

Por razones de extensión queremos centrar este trabajo en el análisis de algunos aspectos concretos: la diversidad tipológica de complejos funerarios, su distribución espacial y los vestigios que quedan del paleopaisaje funerario de esta necrópolis. También nos interesa avanzar algunas de las características del tipo común de los complejos funerarios, centrándonos, sobre todo, en los pozos de acceso. Finalmente ensayaremos una secuencia cronológica de los ritos de enterramiento documentados en esta necrópolis, ordenando todos los episodios conocidos. Esperamos que estas novedades, a las que se ha llegado sin realizar nuevas excavaciones, sirvan de botón de muestra sobre la información que todavía guarda este yacimiento.

\section{Variedad tipológica de complejos funerarios}

En primer lugar, se debe matizar la idea, devenida en un auténtico topos, de que esta necrópolis occidental se caracteriza por la existencia de los complejos funerarios que hemos denominado de tipo común y tipos singulares. Frente a esa reducción, la información recopilada muestra una realidad más compleja y variada. Variedad que, estaba presente - si bien de forma tímidaen las obras escritas por los autores de las excavaciones, o quienes habían manejado sus datos, pero que con el tiempo se ha ido pretiriendo.

El detallado «Diario de excavaciones» de Juan Fernández López revela una densa ocupación de todo el espacio de la Necrópolis Romana. Será la propia dinámica de excavación la que relegue casi al olvido las estructuras funerarias distintas de los sepulcros hipogeos, homogeneizando un panorama de vestigios desprovisto de su riqueza inicial, y permaneciendo las tumbas hipogeas como las únicas evidencias del uso funerario dado a este espacio.

Entre los numerosos casos documentados, podemos citar a modo de ejemplo los hallazgos efectuados en los alrededores de la tumba de los Cuatro Departamentos. En una superficie de dos metros cuadrados en el entorno de su pozo de acceso, se encontró una sepultura de cremación, bajo un tejadillo de tegulae, amén de otros vestigios sin calificar. Este bustum puede fecharse con probabilidad en el siglo II de nuestra era, por la presencia de ungüentarios de los tipos Ising 82.A1 y 82.B2, reconocibles por su forma característica en los someros dibujos de las piezas. Algún tiempo después volvió a encontrarse en ese mismo entorno otro bustum, esta vez sin cubierta de tegulae, con una pequeña caja con cerradura, cadena, asa y llave. Dentro, dos ungüentarios y un espejo, entre otros objetos que no dibuja ${ }^{8}$.

Esta densidad de ocupación también ha sido reflejada en las referidas excavaciones que se están llevando a cabo en el solar frontero a la Corredera, bajo la dirección de los arqueólogos municipales de Carmona. Entre los tres complejos hipogeos, se han podido documentar igualmente un ustrinum, sobre el que había volcado una vasija grande, en forma de cuenco semiesférico, dos inhumaciones y alineaciones de muros, aún en curso de exhumación.

De igual forma, las tomas fotográficas aéreas realizadas para elaboración del modelo digital terrestre, que forma parte del SICAC, han permitido localizar, en la finca donde se ubica el anfiteatro, las huellas de estructuras circulares con fosa central, situadas junto a la vía Augusta, tipología a la que también responden posiblemente los restos ubicados junto al actual museo $\mathrm{y}$, en este segundo caso con toda seguridad, otro complejo excavado a finales del siglo XIX al norte del anfiteatro, en el denominado campo de Manta (Fernández López 1886: 26-28; Bonsor 1899b: 75, fig. 72, con rectificación sobre su ubicación en Bonsor 1931: 76 s.). Este tipo difiere de los mausoleos circulares por carecer de cámaras infrayacentes, lo que permite aumentar el elenco de las variedades de enterramiento presentes en la necrópolis.

Los levantamientos de los complejos funerarios ya excavados por Bonsor también aportan asimismo nuevas evidencias, sobre todo acerca de la introducción de fosas destinadas a las inhumaciones dentro de las criptas hipogeas. En efecto, aunque la cuestión ya había sido señalada con anterioridad cuando los autores trataban las tumbas de las Cuatro Columnas, de Postumio y del Ustrinum, que poseen fosas destinadas a esta finalidad, la tumba D4b9019 ${ }^{9}$, situada junto a la valla delimitadora del recinto, no solo ofrece un nuevo ejemplo de esta convivencia, sino que

8. ACAC III.1.3. caja 1, libro 3 [Juan Fernández López] «Diario de excavaciones 1884-1905», ff. 014 y 027.

9. Estas referencias hacen alusión a la denominación de los complejos funerarios en el SICAC. La combinación alfanumérica se ha establecido de acuerdo a un sistema de cuadrículas designadas con letras mayúsculas y números, subdivididas en otras etiquetadas con letras minúsculas y números y, dentro de cada una de ellas, los complejos estructurales, ustrina y rasgos o huellas en la roca que puedan asociarse a ellos se han numerado del 01 en adelante en sentido horario. No obstante, a los complejos con nombres acuñados en la bibliografía se les ha respetado esa designación en aras de favorecer la comprensión de este texto. 


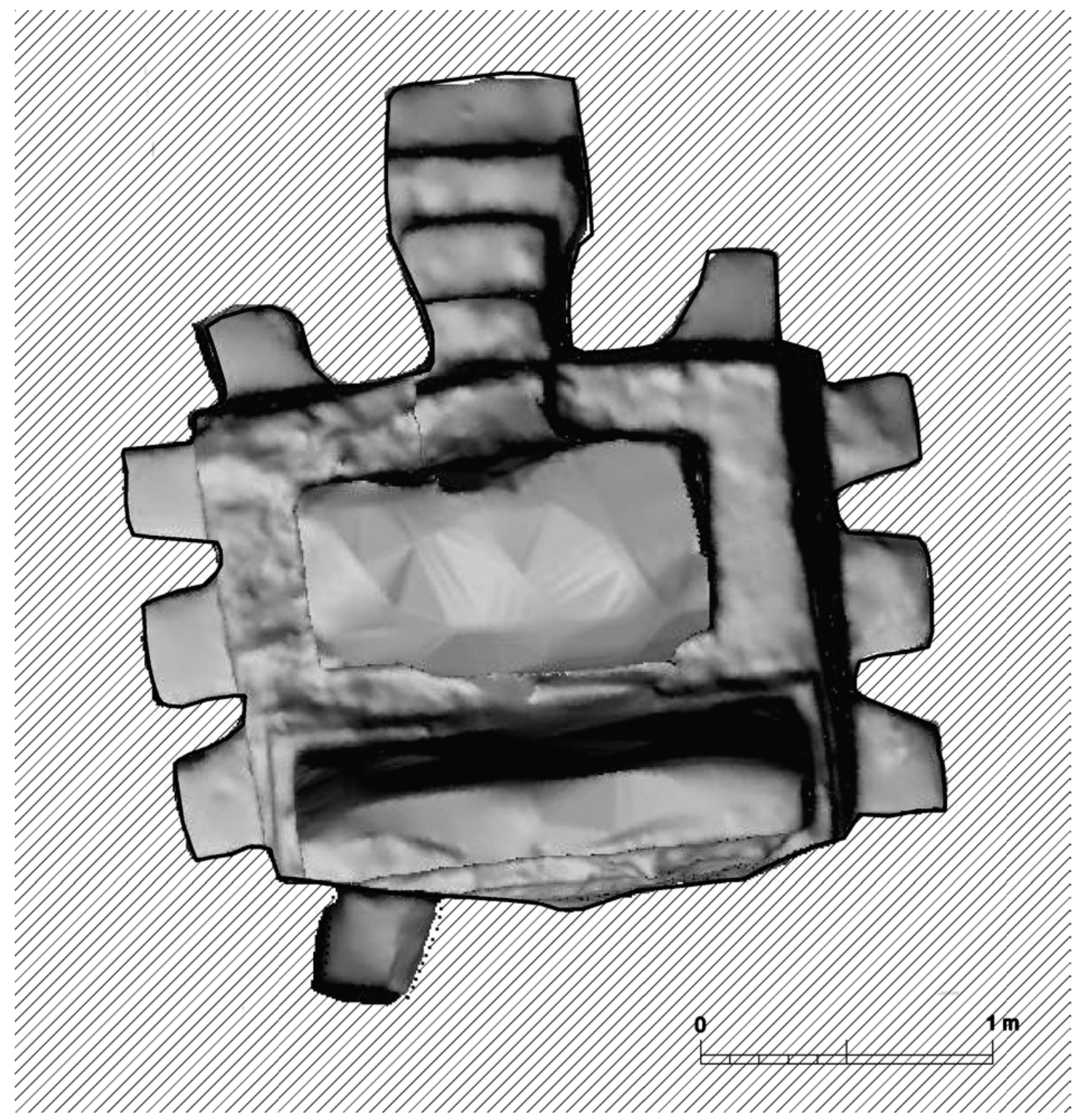

Figura 3. SICAC. Planta de la tumba D4b901.

plantea la posibilidad de que la reforma para introducir la inhumación sea posterior al diseño original de la cámara. Secuencia que podría indicarse por la distribución irregular de los nichos en el nuevo espacio creado (figura 3 ).

A expensas de lo que resulte de un estudio más detallado de la tumba de Servilia, de momento, puede apuntarse que la famosa sala subterránea con cúpula y arcos de refuerzo, no sería un vestíbulo como ha venido siendo interpretada (Bendala Galán 1976: 74), sino la auténtica cámara funeraria, con arcosolios formados por la arquería interior de refuerzo de la cúpula excavada en la roca, destinada a inhumaciones en sarcófagos de piedra, uno de los cuales fue hallado in situ, aunque en posición secundaria, según muestran las fotos de la intervención realizada

ISSN: 1133-4525 ISSN-e: 2255-3924 http://dx.doi.org/10.12795/spal.2012.i21.08 


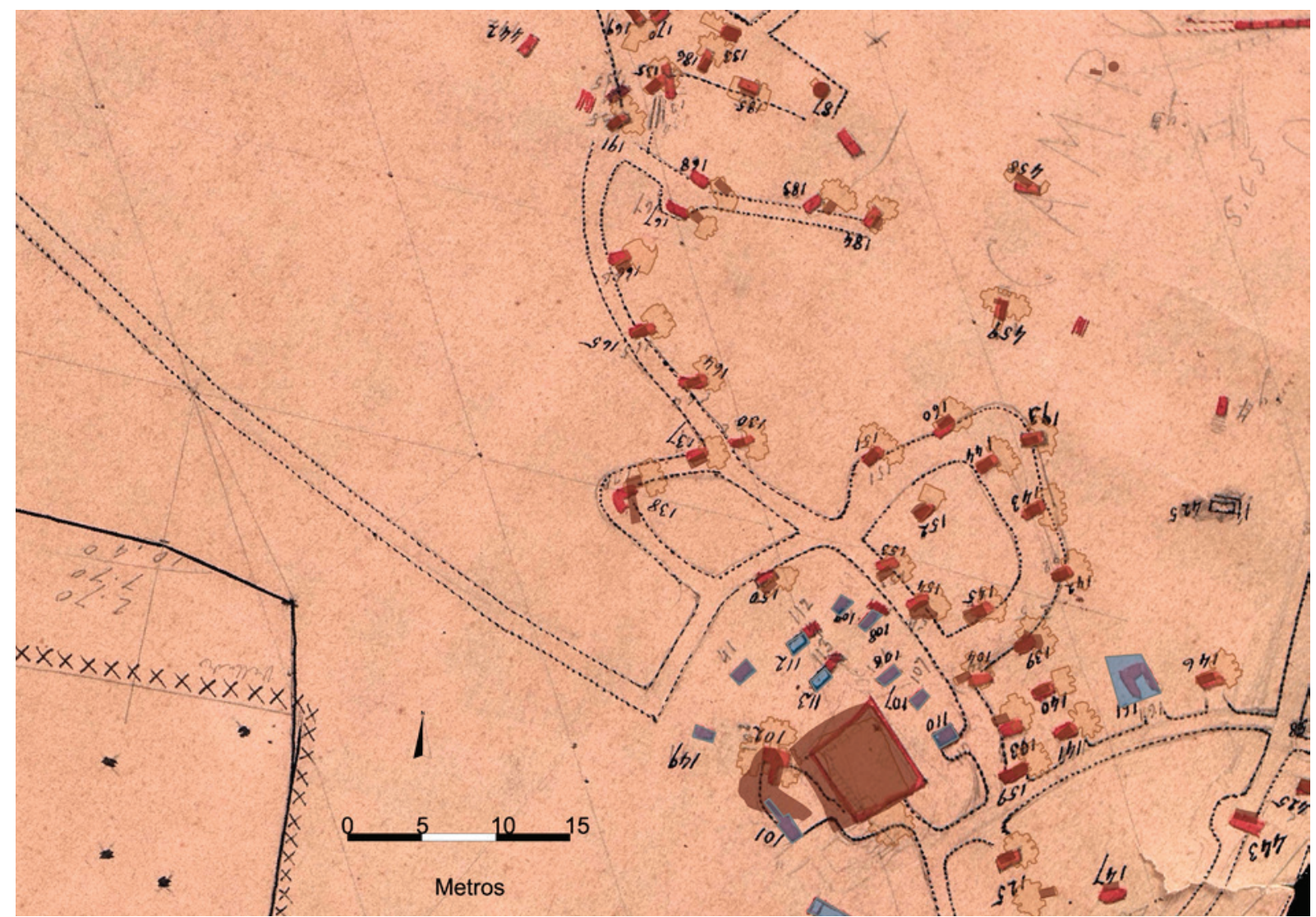

Figura 4. Planta compuesta del SICAC con levantamientos de las tumbas integrados en el plano de excavaciones de Bonsor.

por Fernández López en 1905 (Ruiz Cecilia et alii 2011: 132 s. $)^{10}$. Estos sarcófagos se dispondrían en los espacios reservados entre los arcos. Esta cámara para inhumaciones se comunica con otra, con banco corrido, destinada a recibir las incineraciones. Sobre la función de esta segunda cámara nunca ha existido la menor duda, a pesar de carecer de nichos para ese fecto.

\section{Distribución espacial}

La finalización del registro fotogramétrico de la necrópolis nos permite, por vez primera, mostrar una planta completa de la distribución de los complejos funerarios actualmente reconocibles, combinada con los que han dejado constancia de su existencia en los

10. Este sarcófago se instaló con posterioridad en la sala del pasillo hipogeo. planos generales de las excavaciones levantados por George E. Bonsor (figura 4) ${ }^{11}$.

Esta nueva visión consiente realizar una aproximación al patrón de desarrollo espacial de los complejos funerarios hipogeos. Las tumbas conocidas que, como ya se ha mencionado no representan en modo alguno el monto total de las que debieron existir ${ }^{12}$, se ordenan siguiendo

11. Se conocen dos planos. Uno fue el entregado por Bonsor y Fernández López a De la Rada y Delgado, que aparece en la publicación de este. El otro, con mayor número de hallazgos, pero del que solo se conservan tres fragmentos, se halla custodiado en el Fondo Bonsor del Archivo General de Andalucía.

12. Durante los recientes trabajos de eliminación de las terreras del entorno de la tumba de las Guirnaldas, construidas por Fernández López y Bonsor con la tierra sobrante de las excavaciones, se halló el pozo de acceso de una tumba, posiblemente de una sola cámara -según indicó la prospección geofísica-, que estaba estucado. Por cuestiones de conservación no se excavó, pero lo importante ahora es señalar que no se encuentra entre las registradas por Bonsor y Fernández López. También al eliminar el recrecimiento artificial realizado sobre el acceso a la tumba del Elefante, se halló parte del zócalo del cerramiento original de este complejo (Ruiz Cecilia et alii 2011). 
los ejes viarios principales que transcurren por ese sector del área periurbana carmonense, aspecto reiterado por toda la bibliografía. Los principales viales son la vía $\mathrm{Au}-$ gusta, que bordea por el sur el edificio del anfiteatro ${ }^{13}$, y otras que conducían hacia Hispalis de forma más directa. Una de estas últimas lo hacía a través de la vereda de Sevilla (Amores, Rodríguez-Bobada y Sáez 2001 y Amores Carredano 2001). Parte de esta vía habría sido excavada por Fernández López y Bonsor en el campo de las Canteras, según interpretación de Jiménez Hernández (2007). Pensamos que esta propuesta de identificación del fragmento de vía aparecida en las excavaciones de Fernández López y Bonsor resulta más verosímil que considerarla como una vía de servicio para el trabajo en las canteras, finalidad con la que ha trascendido para un sector de la investigación. Como se verá, esta identificación no resulta en modo alguno baladí para la interpretación de las tumbas que se asoman a ella.

La ordenación de los complejos funerarios de la necrópolis no es caprichosa o espontánea, sino que busca un especial efecto escénico, mostrando una auténtica fachada de recintos que albergan tumbas relevantes, apoyándose también en la orografía acolinada del terreno. He aquí algunos datos relevantes de esta ordenación.

A los márgenes de este tramo de vía Augusta, se alinea el mayor número conocido de ejemplares de un tipo de tumba muy específico en Carmona, compuesto por aquellas que tienen un triclinio funerario emplazado en patio excavado en el terreno. Estos elementos suelen estar asociados a un pozo y otras dependencias o ámbitos funcionales relacionados con la preparación de los silicernia y otros banquetes rituales. Fernández López, en el mencionado «Diario de excavaciones», da cuenta de cinco de ellos. Ordenados de este a oeste: la tumba del Elefante, el triclinio del Olivo, el que debió existir bajo la sede actual del museo de sitio del CAC, el Columbario-Triclinio y, finalmente, uno del que únicamente es conocida su localización bajo la actual avenida Jorge Bonsor. Sin embargo, hay otros datos que apuntan a un número mayor de enterramientos de este tipo. Manuel Fernández López (1899: 7) sitúa bajo la actual avenida Jorge Bonsor, otro más, que al parecer pasó desapercibido a su hermano Juan. A ellas habría que sumar la estructura número 402 del Itinerario de la Necrópolis Romana de Carmona de 1899, donde se lee: «Pozo de agua que debió pertenecer a un recinto funerario, con triclinio hoy destruido» (Itinerario de la $\mathrm{Ne}$ crópolis Romana... 1899: 27 s.). Concentración que no

13. Este sector fue objeto de excavación a comienzos de la década de los ochenta del pasado siglo (Belén, Lineros et alii 1987). se repite en ningún sector de la necrópolis occidental. De hecho, el otro ejemplar de este tipo de complejos del que se tenga conocimiento, la llamada tumba de Nemesio (Fernández López 1899: 32 s.), situada en el cercado de Luisa, a espaldas del extinto convento de San Francisco, también está en las proximidades de la vía Augusta (figura 5) ${ }^{14}$. Por ese tramo de la vía, cercano al citado convento, también se excavó otra tumba de tipología singular, pero no puede calificarse como triclinio funerario, a tenor de la descripción literal que nos ha quedado de ella. Apareció en el cercado de Monago, situado en la manzana existente entre las actuales calles Anfiteatro, Atarazanillas, el anfiteatro y un molino, hoy día demolido, que daba fachada a la avenida Jorge Bonsor. Estaba constituida por una escalera que conducía a «cuatro corredores con podio y hornacinas, cuyos corredores tienen ocho puertas, dos cada uno que se abren, o dan paso, a un espacio cuadrado o patio que tiene una apertura circular en su parte alta y media» ${ }^{15}$.

14. Esta tumba fue excavada por el sr. Thys, ingeniero belga, en octubre de 1896. Su planta se compone de una escalera de acceso de seis peldaños que da lugar a un vestíbulo acodado en ángulo recto. Este termina en un pasillo al que se abren sendas cámaras opuestas con seis y siete nichos respectivamente. El pasillo termina en patio abierto en cuyas paredes aparecen hornacinas de mayor tamaño de las destinadas a las urnas cinerarias, algunas de las cuales presentan arcos apuntados (posiblemente como el existente en la tumba de la Moneda de Vespasiano), así como otra cámara funeraria, más pequeña con cuatro hornacinas. El patio, que suponemos a cielo abierto, está ocupado por un triclinio con su mensa, circundada por un canal que desagua en una pequeña piscina. El lado por donde desemboca el pasillo a este patio está conformado con seis arcos de los que se advierten los pilares, formando una auténtica fachada. En sus extremos se abren sendas estancias, una de las cuales presenta una hornacina amplia y la otra un pozo. Esta tumba, a pesar de que su planta ha permanecido inédita hasta ahora, ha alcanzado cierta notoriedad habida cuenta del hallazgo en su interior de una plaquita metálica con una inscripción dedicada a Némesis (CILA Se, 841). Esta placa se dio a conocer por Manuel Fernández López (1899: 36 s.) y siempre se había considerado como perteneciente a un contexto fúnebre. Sin embargo, en el ámbito de sus estudios sobre el culto nemesiaco, J. Beltrán Fortes (2001a: 202), la considera procedente posiblemente del propio anfiteatro, lo que vendría avalado por la nueva lectura dada por A. Stylow (2001), para quien las dos primeras letras no serían $D$ (is) M(anibus), sino $O M$, que podrían pertenecer al nombre griego de un siervo público (Delom(---), de Diomas o Diomedes, o bien Demo(---)). A. Canto en HE 11 (2001 n 448: pp. 114 s.) propone otro nombre de la persona dedicante, también griego $(O m / p(h) e)$. Por supuesto, no pretendemos dar nuevas lecturas de la placa, pero sí resolver su innegable procedencia funeraria, concretamente del pozo de este complejo. Posiblemente se trataría de un collegium funeraticium al que pertenecería esta persona de condición servil. Sobre la datación de la tumba, solo podemos señalar que, a juzgar por la moneda de Domiciano encontrada en ella aunque desconozcamos el contexto, estaría en uso en época flavia.

15. ACAC III.1.3. caja 1, libro 3 [Juan Fernández López] «Diario de excavaciones $1884-1905 »$ fol. $103 \mathrm{v}$. 


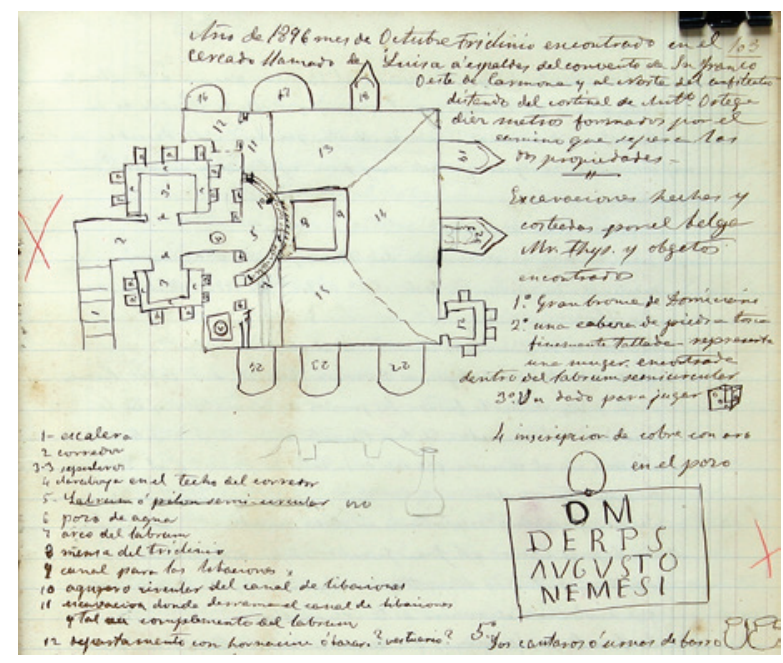

Figura 5. ACAC. Croquis de la tumba de Nemesio.

S. R. Braune (2008: 98 ss.) establece una relación entre el Columbario-Triclinio, el triclinio del Olivo y la tumba del Elefante ${ }^{16}$ con ejemplares análogos italianos: salvo que en esos casos las construcciones no están rebajadas en la roca, como ocurre en Carmona, característica que achaca al fuerte influjo local de origen cartaginés. En todo caso, fecha esos complejos en el siglo I de nuestra era, lo que coincide con la datación dada por autores anteriores (Bendala Galán 1976: passim), así como con las escasas referencias cronológicas recogidas durante su excavación ${ }^{17}$.

En el tramo de vía a Hispalis excavado en la $\mathrm{Ne}$ crópolis Romana por Fernández López y Bonsor se documentaron más de veinte tumbas (Fernández López 1886: 18 n. 2). De entre ellas destaca un conjunto alineado en el frente derecho de cinco mausoleos circulares (figura 6), conformando una fachada claramente intencional, reforzada por las estructuras emergentes de los complejos situados en segunda línea, como el denominado mausoleo Cuadrangular y la tumba de las Cuatro Columnas.

Como se ha mencionado, Bendala Galán (2002: 148 s.) atribuye a este tipo de construcciones una cronología posterior al de los complejos de pozo y cámara

16. A la que también niega el carácter de santuario de los dioses Cibeles y Attis

17. Una vez amortizado el triclinio del Olivo, su espacio fue reutilizado para un nuevo enterramiento, en este caso una cremación individual bajo tejadillo a dos aguas de tegulae, que podría datarse en el siglo II de nuestra era, a tenor del ungüentario tipo Ising 82.A1 encontrado entre su ajuar. Ver ACAC III.1.3. caja 1, libro 3 [Juan Fernández López] «Diario de excavaciones 1884-1905» fol. 014v. hipogea, producto de una sociedad ya plenamente romanizada, que ha transformado las iniciales señas identitarias y, acerca de esta alineación, la considera residual habida cuenta de su alejamiento de la ciudad y la escasa importancia de la vía.

Sin embargo, es difícil seguir manteniendo esta interpretación pues el mencionado carácter secundario de esta vía, aunque no se trate de la vía Augusta, queda en entredicho por la misma tipología monumental de estas tumbas, dotadas de una estructura emergente en forma de túmulo. Además, con independencia de su proximidad o no a la ciudad, los indicadores cronológicos del entorno remiten al siglo I d. C. De esta manera, la decoración pictórica de la tumba de Servilia parece terminada hacia época de Nerón (Mostalac Carrillo 1999: 187) y, en el otro extremo de esta alineación de los denominados mausoleos circulares, la tumba de Prepusa parece ser casi coetánea, pues una de las urnas de este sepultura familiar está fechada por criterios epigráficos hacia finales del siglo I d. C. (Stylow 2001: 102). Por último, en la misma zona, la única aproximación cronológica conocida sobre el periodo en que estuvo en uso la tumba de las Cuatro Columnas la aporta una moneda de Colonia Patricia $^{18}$ que resulta perfectamente coherente con las anteriores. Luego no cabe fechar este complejo fuera de este marco cronológico.

Marco que es extensivo al resto de las tumbas del mismo tipo dentro del área comprendida por el Conjunto Arqueológico de Carmona. En efecto, como es bien conocido, muchas de ellas tuvieron una rica decoración pictórica en las cámaras. Los estudios más recientes (Mostalac Carrillo 1999), siguen fechando todas las muestras conocidas en el siglo I d. C., con independencia de que se trate de tumbas pertenecientes al tipo común o sean singulares.

Tampoco parece que la monumentalización de las cámaras haya sido el motor del cambio de las tumbas del tipo común a los denominados mausoleos circulares, pues junto a la tumba de Prepusa se halla otra totalmente construida con sillares que responde al tipo común de pozo y cámara simple con banco y nichos (C2h101 en el SICAC, número 13 de las excavadas por Fernández López y Bonsor).

Sin duda, debió existir una secuencia de construcción de estos complejos funerarios, pero, de momento, todos los marcadores cronológicos conocidos no permiten el establecimiento de una sucesión concreta. Quizás las preferencias por un tipo u otro de complejo funerario se deban a cuestiones socioeconómicas y de prestigio

18. Fernández López 1886: 28. 


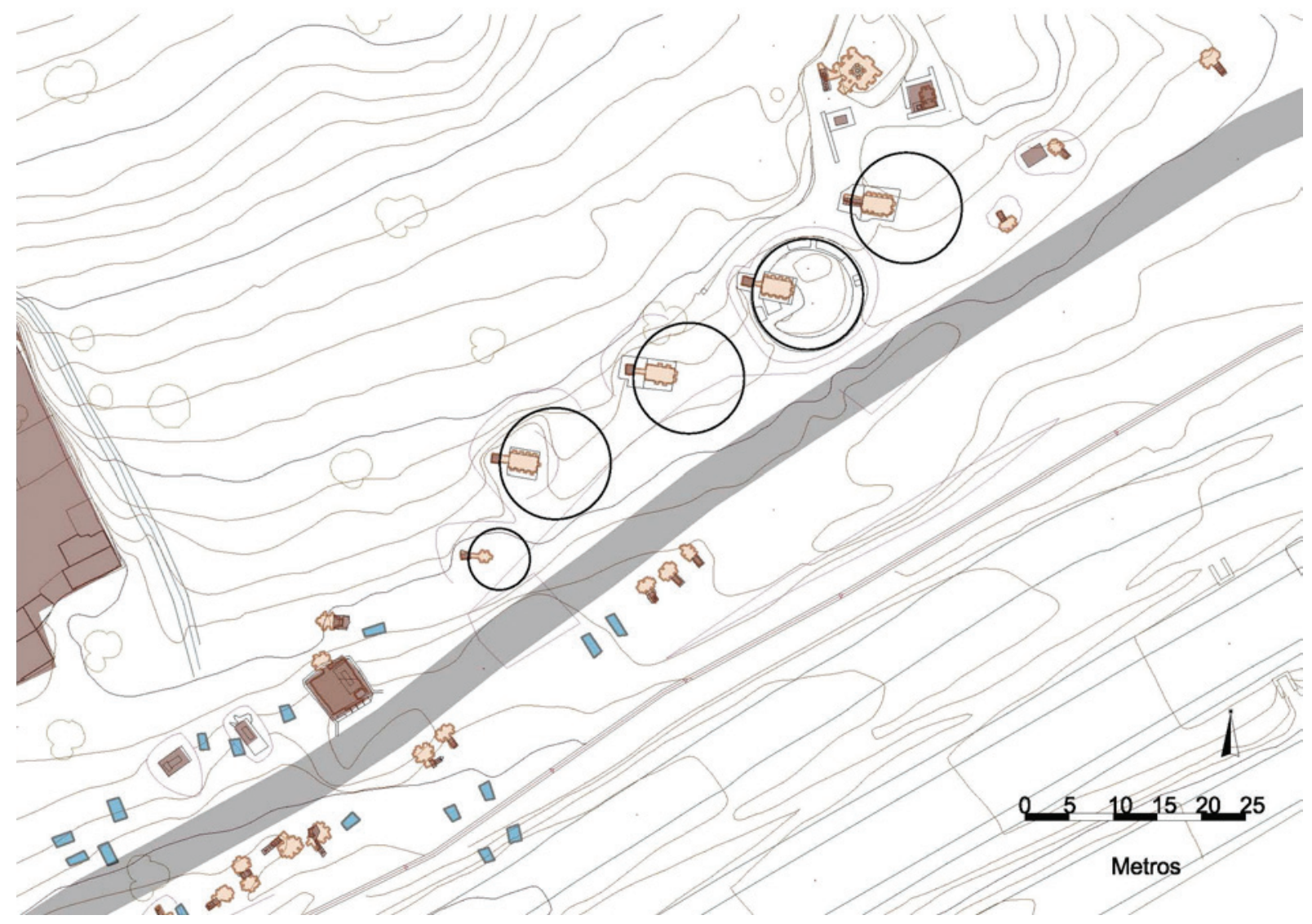

Figura 6. SICAC alineación de mausoleos circulares al norte de una de las vías a Hispalis.

y no, necesariamente, a una progresiva romanización, dado que la estructuración interna de este coemeterium apunta a una sociedad muy familiarizada con las modas y los usos itálicos, como veremos a continuación.

\section{Paleopaisaje funerario}

El estudio y reconocimiento sobre el terreno, que venimos realizando en estos últimos años, muestra alguna información relevante para dar una idea de la ordenación interior de este sector de la necrópolis occidental de Carmo.

A pesar de la enorme erosión de ladera experimentada por el lugar y del expolio sistemático de sillares del que fueron objeto los monumentos de la necrópolis, a partir de mediados del siglo XVI (Bonsor 1931: 39), así como de las transformaciones operadas para ajardinar el espacio comprendido dentro de la Necrópolis Romana por Bonsor y Fernández López (Gómez Díaz 2006), quedan vestigios del paleopaisaje funerario indicativos de la disposición ordenada de los complejos funerarios.

En concreto, unos metros más arriba de la tumba de Postumio se observa sobre el terreno una alineación de sillares en escuadra que delimitan un recinto cuadrangular (E4b301, numerado por Bonsor como 161), parcialmente destruido. En su interior no se aprecia ninguna cripta, aunque para confirmar este extremo debe desmontarse previamente el parterre que lo oculta en parte (figura 7).

En otro extremo de la Conjunto Arqueológico, algo más abajo de la tumba de las Cuatro Columnas, sirviendo de límite al ustrinum tradicionalmente asociado a esa tumba (D2d701, numerado por Bonsor como 366), es también visible otra alineación rectilínea de sillares, coherente con el área subterránea ocupada por la tumba de las Cuatro Columnas (figura 8). Esta alineación resulta sensiblemente paralela a la delimitación, también a base de muros de sillares del mismo tipo que en los dos casos anteriores, del denominado mausoleo Cuadrangular. 


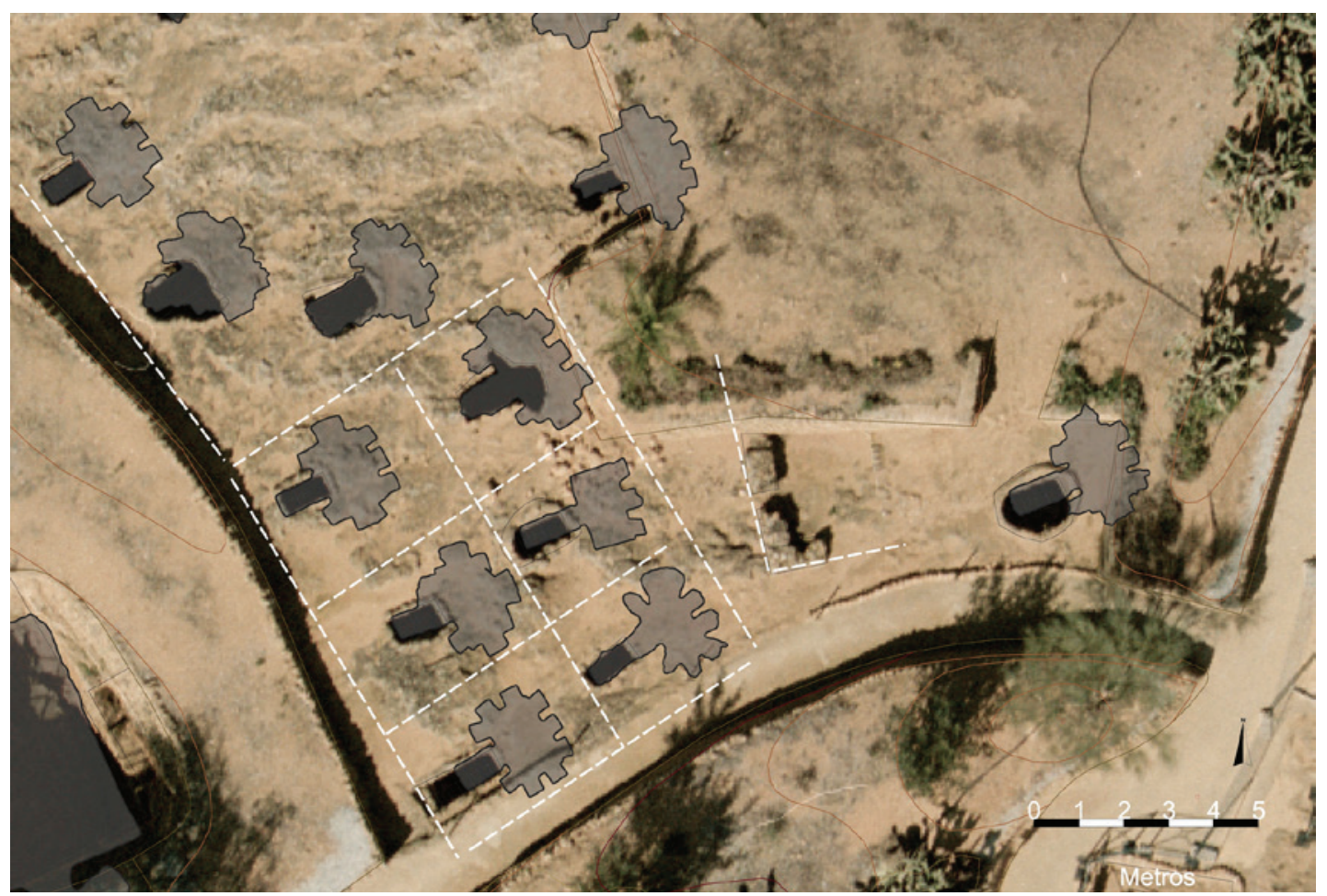

Figura 7. SICAC. Sector del entorno de la tumba de Postumio con indicación de las alineaciones que delimitan los acotados funerarios.

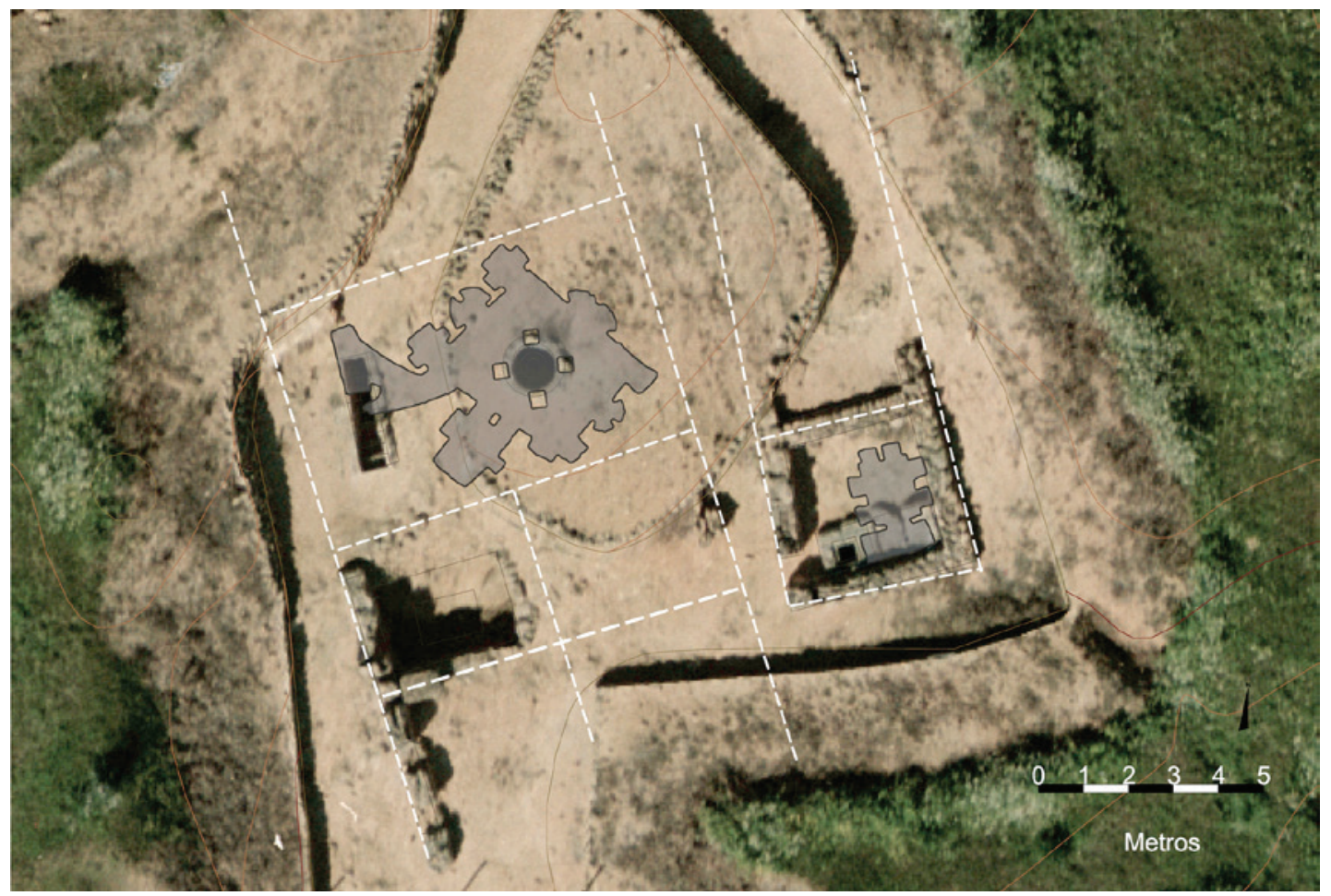

Figura 8. SICAC. Sector de la tumba de las Cuatro Columnas con indicación de las alineaciones que delimitan los acotados funerarios 
El patrón de distribución de las tumbas conocidas, adaptado a los ejes viarios y a las curvas de nivel de la orografía, permite presuponer la existencia de lotes o acotados funerarios, cuyas dimensiones se adaptan sin problemas a las áreas ocupadas por las cámaras subterráneas. Incluso se perciben espacios para el tránsito entre las alineaciones de recintos, a modo de vías funerarias. El mencionado mausoleo Cuadrangular debe interpretarse como un ejemplar relicto de este tipo de acotados.

Para averiguar la superficie media de estos recintos solo podemos partir, como indicador seguro, de las del mausoleo Cuadrangular: 14 x 14 pies romanos. No obstante, interpolando líneas, a título de mera hipótesis, resultan unas parcelas en las que encajan las tumbas conocidas, cuyos tamaños están mayoritariamente comprendidos en un rango entre 100 y 200 pies cuadrados, común en la Bética, a tenor de los datos conocidos por las inscripciones con indicatio pedaturae (Vaquerizo y Sánchez 2008).

No puede extrañar la existencia de estos acotados, ya que, en el sector comprendido entre el anfiteatro y la avenida Jorge Bonsor ${ }^{19}$, María Belén y su equipo reconocieron vestigios constructivos que les inducían a pensar en la existencia de recintos funerarios, con amplios caminos que permitiesen la circulación por el interior de ese sector la necrópolis (Belén, Gil et alii 1985: 53).

Tampoco podemos dejar de mencionar el fragmento de inscripción con indicación de pedatura, que perteneció a la colección particular de Mateos Gago (CIL II Suppl. $5414 \rightarrow$ Stylow 2001: 102; CILA Sev 865) ${ }^{20}$, único ejemplar conocido en Carmona. Su procedencia de la necrópolis es dudosa, si bien es conocida la relación de Mateos Gago con los hermanos Fernández López. En cualquier caso, y con independencia de que indique la longitud del camino o el lado de un locus, y tanto si se leen cincuenta o cincuenta y cinco pies ${ }^{21}$, encajaría con el panorama que venimos describiendo.

No obstante, falta más información sobre la extensión de estas delimitaciones, cuya virtualidad -de momento- solo podemos atribuir a estas áreas del sector comprendido entre las dos vías (la Augusta y la que conduce de forma directa a Híspalis), que delimitan grosso modo el área musealizada en el Conjunto Arqueológico de Carmona. Carecemos de evidencias

19. Que divide las fincas urbanas del anfiteatro y la necrópolis del Conjunto Arqueológico de Carmona

20. Para una comprensión como camino privado que dirige a un locus sepulturae, Rodríguez Neila 1983: 182 y Melchor Gil 1992: 136.

21. Debe tenerse presente que, por ejemplo, la parcela que contuviese un mausoleo circular debería tener en torno a quince o dieciséis metros de lado. sobre la extensión de esta práctica (y sobre todo la delimitación de lotes mediante recintos) al resto de la necrópolis occidental ${ }^{22}$.

Inextricablemente ligado a cuanto se ha mencionado en los párrafos anteriores, está uno de los grandes interrogantes que ha planeado sobre esta necrópolis: dilucidar qué supraestructura completaba a las subterráneas en los complejos funerarios. Manuel Fernández López (1886: 24), que recoge el parecer de su hermano Juan y de George E. Bonsor, divide las tumbas en dos partes: el sepulcro, o estructuras hipogeas, y los mausoleos, que serían las construcciones emergentes sobre el terreno. De su existencia no duda, aunque no hayan sido encontradas con un grado de conservación suficiente como para ser reconocidas como tales. Atribuye esa función a los "cimientos cuadrados o circulares" que rodean los sepulcros de cierta importancia. Asimismo advierte de la presencia de rebajes tallados en la roca junto a los accesos a los pozos. Para él se trata de sujeciones para cipos o columnas exteriores.

Para Collantes de Terán (Hernández, Sancho y Collantes de Terán 1943: 100-102) era evidente que muchas de estas tumbas, además de los cipos, estelas y columnas que indicaran su existencia al exterior, tuvieron también superpuestas construcciones de más importancia, verdaderos mausoleos, con recintos donde se reunían los familiares del difunto en los días señalados para las conmemoraciones y ceremonias fúnebres. No de otra manera se explica la existencia en algunas de ellas de aberturas hechas en la bóveda a modo de claraboyas, en comunicación con el exterior, como ocurre por ejemplo en la tumba de las Cuatro Columnas o la de la Moneda de Vespasiano. También observó algún vestigio de estos mausoleos, concretamente en la tumba de las Guirnaldas, donde se aprecia la existencia de un muro entre el pozo de entrada y el ustrinum. Por otra parte, también reproduce la certeza anterior acerca de la indubitable existencia de superestructuras en los mausoleos circulares

Manuel Bendala, en su tesis, apunta la pérdida que supone para el conocimiento de la necrópolis la imposibilidad de estudio de las partes exteriores de las tumbas, de las que no ha quedado apenas rastro. Destrucción

22. La excavación en extensión del solar frontero a la Corredera, actualmente en curso, donde hasta el momento -como ya se ha indicado- han aparecido tres complejos funerarios de pozo y cámara, será importante para comprobar la existencia o no de recintos más al este del CAC. Por otra parte, en la necrópolis norte, María Belén y su equipo advirtieron la presencia de estos acotados delimitados por muros con aparejo de piedras y fragmentos de ladrillos (Belén, Gil et alii 1985: 57). 
responsable, asimismo, de la escasez de epigrafía funeraria en la necrópolis carmonense, cuya ubicación sería sobre la superficie (Bendala Galán 1976: 35). Años más tarde, insiste en que, pese a la ignorancia que tenemos sobre la apariencia de las tumbas, se barrunta su escasa proyección exterior, de modo que se configura una necrópolis con una disposición que más parecería recordar la propia de cementerios fenicio-púnicos, como Puig des Molins, cifrando su monumentalización a la aparición de los mausoleos circulares y otras tumbas singulares, como ya se ha mencionado (Bendala Galán 2002: 153).

A falta de nuevos datos significativos, no puede avanzarse mucho sobre este particular, aunque cabe poner en conjunto todos los disponibles. En primer lugar, parece perfectamente asumible la intuición de M. Bendala sobre la escasa proyección exterior de los complejos funerarios de cámara hipogea y pozo, estuviesen o no incluidos en un acotado funerario. No obstante, los indicios sugieren la existencia de episemata en este tipo de complejos, a lo que habría de añadirse aquellos otros donde la intención de monumentalización exterior resulta evidente. En efecto, algunos rebajes y entalladuras encontrados en el entorno de los pozos de acceso, apuntan a que sirviesen para colocar elementos verticales, ya fuesen aras u otro tipo cualquiera de señalización (estelas o cipos). La ausencia de epígrafes con este tipo de formato no puede tomarse como prueba de su inexistencia, pues el monto de los epígrafes conservados en bastante somero.

Por otra parte, hubo un deseo expreso de monumentalización del lugar a base de estructuras exteriores, ya fuesen con los mausoleos circulares ya con otro tipo de construcciones de carácter tumular como la excavada en el campo de Manta, o en el entorno del actual museo de donde procede un fragmento de placa de mármol con un epígrafe incompleto (CILA Se $874=$ HEp 11, $449=\mathrm{AE} 2001,1192$ ), posiblemente situado en uno de sus frentes, relativo a una institución o cargo municipal (Stylow 2001: 100, pace A. Canto en HEp).

La tumba de Servilia resalta por la singularidad de su planta y concepción, pero un futuro análisis completo de este conjunto y sus alrededores habrá de mostrarnos su indudable proyección exterior. De la tumba del Elefante existen pruebas indirectas, ya que del relato de su excavación pocos datos pueden extraerse (Fernández López 1899), de la aparición de abrazaderas metálicas para puertas (Bonsor 1899a: 427). Tampoco deben olvidarse las noticias referentes a enormes sillares aparecidos en las tumbas de patio, como la de Postumio y Prepusa (Fernández López 1886: 24-26 y
29-33), que deberían pertenecer tanto al cerramiento, como a la formalización de algún elemento arquitectónico de carácter monumental.

A estos deben añadirse aquellos otros, de fisonomía ignota, situados sobre las infraestructuras funerarias caracterizadas por presentar un óculo en la bóveda de las cámaras. Es de suponer que hacia el exterior hubiese algún tipo de edificación que lo cobijase, como ya pensó Collantes de Terán. No sería extraño que estas supraestructuras fuesen livianas, con pérgolas y elementos vegetales. En algunos complejos, como la tumba del Elefante, de Postumio o el Columbario-Triclinio hay rebajes en la roca que pudieron usarse para plantar especies vegetales, especialmente en las áreas donde se realizaba el convivium funebre. Estas zonas suelen emplear opus signinum, del que solo quedan algunos restos aislados, como pavimento adecuado para la intemperie.

Efectos de monumentalización reforzados por las alineaciones frente a las importantes vías que comunicaban la ciudad con Hispalis, y por la aludida orografía del terreno dominada por un perfil acolinado. Fuera del ámbito de necrópolis comprendido por el actual Conjunto Arqueológico, la cripta construida en grandes bloques encontrada en el paseo del Estatuto (Anglada y Conlin Hayes 2003b), cuya supraestructura se desconoce, pero se supone monumental si fue acorde con la parte hipogea, puede dar idea de ese mismo deseo de expresión magnificente hacia el exterior.

Como ya se ha mencionado, ninguna evidencia cronológica permite suponer que esta monumentalización es posterior a la proliferación de tumbas de cámara hipogea y pozo; antes bien, pensamos que la construcción de estos hipogeos es manifestación de ese mismo proceso de ostentación.

\section{Consideraciones sobre la tipología de los complejos funerarios}

Como se ha visto, la bibliografía sobre esta necrópolis ha obviado el análisis detallado de las tumbas del tipo común por falta de datos. Aunque el «Diario de excavaciones» fuese accesible a todos los investigadores, hasta hace poco tiempo no se disponía de plantas y secciones de todos los complejos funerarios englobables en esta categoría.

Una vez que el SICAC está ultimado, el análisis de la nueva información permite avanzar ciertas características formales sobre los complejos funerarios más habituales, que posibilitan aproximarnos con detalle 


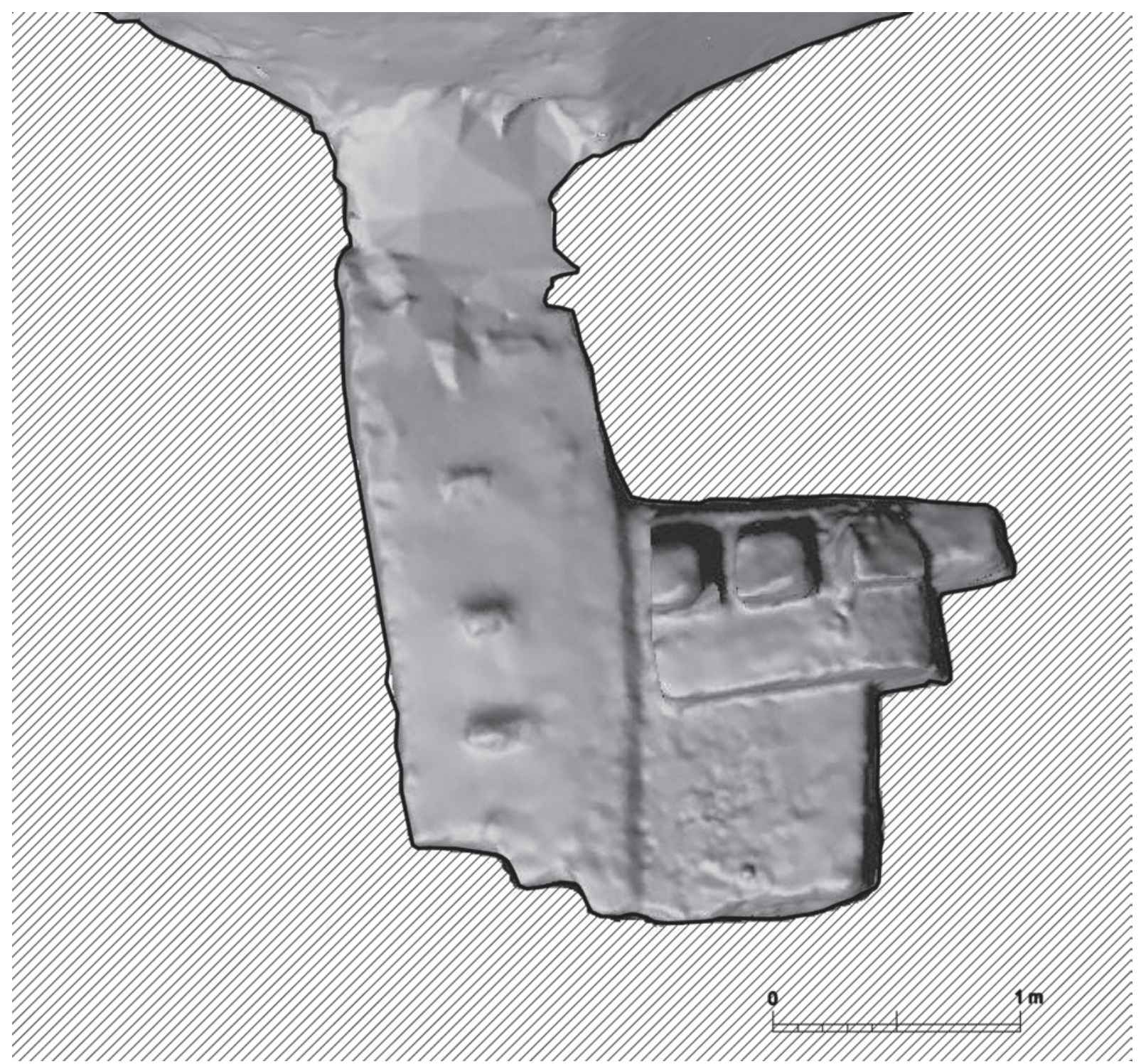

Figura 9. Sección de una tumba en la que se advierta el pozo y dos escalones en el fondo.

a una estructura, los pozos de acceso, que verosímilmente jugó un papel ritual a la par que funcional. Las nuevas excavaciones de tres de estas tumbas en el ya mencionado solar frontero a la Corredera, cercano al $\mathrm{CAC}$, ha arrojado luz sobre algunos aspectos funcionales y rituales y permiten una mejor comprensión de las notas manuscritas de Juan Fernández López.

Toda la bibliografía, prácticamente sin excepciones, ha señalado que en el tipo común el acceso a la/s cámara/s se hacía mediante pozo, con unas entalladuras en las paredes, o escalera. Sin embargo, esta división resulta algo más compleja.
Los pozos suelen ser rectangulares, con una anchura de la mitad aproximadamente de su longitud y una altura entre 2 y 3,5 metros (figura 9). En la mayoría de los casos, terminan en uno, dos o tres escalones, cuya función debía ser facilitar el descenso y ascenso, sobre todo cuando el piso de la cámara se sitúa en un plano inferior al del pozo, circunstancia bastante frecuente en este tipo, aunque también se encuentran pozos, con escalón o sin él, con piso al mismo nivel del de la/s cámara/s. Tanto en unos como en otros casos, la puerta de la cámara se abre al pozo. Esta no ocupa todo el plano de la anchura del pozo, sino que deja sendas 
mochetas a izquierda y derecha del vano de acceso. Esta contigüidad entre pozo y cámara hace imposible la existencia de vestíbulo diferenciado, salvo en único caso (tumba D4e903) donde el tránsito entre pozo y cámara se efectúa a través de un espacio acodado y abovedado, a modo de proyección de la propia cámara. De hecho tiene dos nichos de forma cuadrangular y mayores dimensiones que los de la cámara.

La ausencia de vestíbulo supone que el tipo de cerramiento que tendrían estas tumbas no sería mediante la colocación de sillares ante la puerta de la cámara, pues la inexistencia de espacio libre entre escalones y acceso en muchas de ellas lo impide.

Para facilitar la entrada y el cerramiento de los pozos, la parte superior suele estar hecha a base de sillares, cuando no se recortan estos sobre la roca encajante del complejo. La finalidad es ofrecer una superficie rectangular, sólida y nivelada sobre la que situar las lajas que lo cierran, aspecto sobre el que volveremos algo más adelante. Existen casos que aún mantienen in situ este tipo de terminaciones, aunque el mejor ejemplo de ello lo ofrecen las tres tumbas excavadas en el solar frontero a la Corredera, donde se aprecia la culminación artificial de la obra del pozo realizada a base de un aparejo de sillarejos de calcarenita. Este dato, apreciado con reiteración por Fernández López en su «Diario de excavaciones», sin embargo se ha perdido en muchos de los complejos del Conjunto Arqueológico, debido a que fueron destruidos durante la excavación y restituidos con aparejo de piedras irregulares por Fernández López y Bonsor.

Los pozos tuvieron quizás un revestimiento interno enfoscado en blanco. Así podría deducirse de un complejo localizado en el entorno de la tumba de las Guirnaldas, durante las obras de acondicionamiento de ese sector del Conjunto Arqueológico. No obstante, la tumba no se excavó, por lo que carecemos de confirmación de esta primera evidencia.

La presencia de escaleras responde a dos circunstancias. De un lado, en las tumbas del tipo común suele ser producto de una reforma del acceso, que aún mantienen las antiguas oquedades en las paredes del sistema anterior. De otro, en las tumbas de planta más elaborada forma parte del diseño del complejo. Por ejemplo, en los complejos funerarios caracterizados por dejar un óculo en su bóveda. Aquí la escalera no emboca directamente la puerta de acceso a la cámara, sino que entre ella y la cámara se desarrolla un vestíbulo de tránsito, componiendo un eje acodado entre el sentido del descenso y la entrada a la cámara. En estos casos, el cierre de las tumbas se hacía taponando la puerta de acceso a

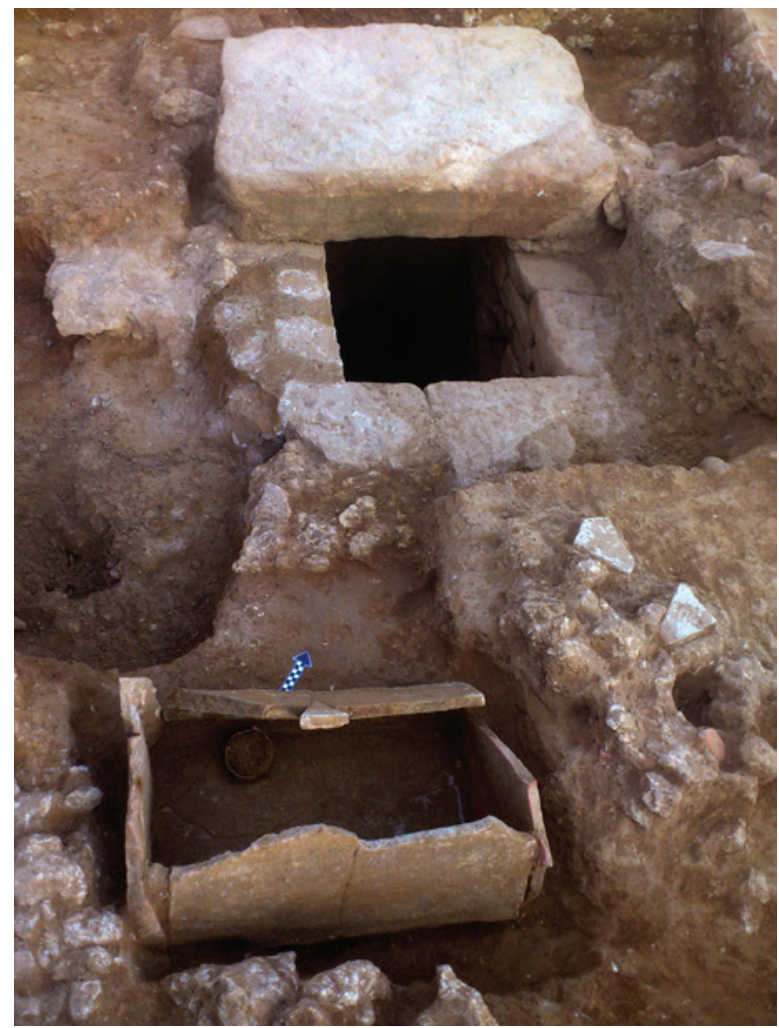

Figura 10: Foto de la excavación del solar frontero a la Corredera donde se aprecia la entrada al pozo de acceso a una de las tumbas y el receptáculo destinado a guardar los vasos para el ritual de las libaciones (foto Juan Manuel Román Rodríguez).

la cámara, como pudo documentar María Belén en la tumba número 72 de las excavadas en el sector del anfiteatro (Belén, Gil et alii 1985) (F5d301 del SICAC).

Los vestíbulos se suelen significar con uno o dos nichos excavados en la pared, de dimensiones mayores que los de la cámara. Como carecemos de constancia sobre qué se hallaba en ellos, no podemos definirnos sobre si fueron ampliaciones para nuevos enterramientos (lo que parece, no obstante, dudoso habida cuenta de que el número de sepelios dentro de la cámara no guarda relación con el de nichos), o bien estaban dedicados a otra función como la de albergar estatuas. A este respecto, debe tenerse presente, por ejemplo, que en la ya mencionada tumba de Nemesio, se encuentran nichos de tamaño reducido en las cámaras funerarias, mientras que en el patio abierto, rodeando el triclinio, hay otros de dimensiones mayores, donde pudo estar el objeto del que colgaba la plaquita con la dedicatoria inscrita.

Aunque, en efecto, existen casos de añadido de escaleras a los pozos originarios, carecemos de elementos 
de juicio que avalen la hipótesis de una mayor antigüedad de los tipos de pozo y cámara simple, frente a los de escalera y cámara compleja. Quizás, de nuevo, más que a diferencias de cronología debamos hacer referencia a distintas funciones: tumbas familiares, en el primer caso, y tumbas colectivas en los segundos.

Por otra parte, las nuevas excavaciones realizadas en el solar frontero a la Corredera han permitido dilucidar ciertos aspectos referidos a la posible función ritual que jugaron los accesos en estos complejos funerarios, lo que está íntimamente relacionado con el tipo de cerramiento que tuvieron y con la posibilidad, apuntada por Manuel Bendala, de que fuesen rellenados ritualmente tras cada sepelio.

En primer lugar, debe señalarse que de las tres tumbas de pozo y cámara excavadas recientemente en el mencionado solar, dos estaban ligeramente alteradas, pero mantenían urnas y ajuar en situación primaria, la tercera había sido despojada de sus enterramientos. En una de las tumbas, que había sido explorada posiblemente en el siglo XIX, accediendo al interior por un lateral del pozo, pero sin escarbar en el interior de la cámara, apareció un vaso de vidrio de forma globular con cuello alto depositado en el pozo, sobre un escalón situado en su fondo. Este hecho se documenta con cierta frecuencia en las excavaciones de Juan Fernández López, a través de las notas escritas en el «Diario de excavaciones». Poca duda cabe sobre la localización in situ de estos ejemplares, que casi siempre son vasos aptos para la realización de libaciones, sean de vidrio o cerámica $^{23}$. Lo cual nos sugiere que, desde el interior de los pozos, se llevasen a cabo determinados ritos que implicase la profusio directamente sobre la cámara, o bien en el propio suelo del pozo $^{24}$. Ello sería imposible si los

23. En ocasiones también se han documentado urnas depositadas sobre los escalones.

24. Apoya la tesis del uso de los pozo en rituales que conllevaran la profusio de líquidos, un reciente hallazgo en el solar frontero a la Corredera. A escasamente un metro de distancia de la entrada de la tercera de las tumbas de pozo excavadas, se ha localizdo un pequeño receptáculo excavado en la tierra, con el interior forrado de tegulae, que también debía cubrir la zona superior aunque había desaparecido, en cuyo interior se encontraba exclusivamente un vaso de paredes finas. Debe recordarse que en esta tumba se encontró en el interior del pozo otro vaso ritual. Para nosotros resulta plausible interpretar este tipo de receptáculos como lugares para guardar los vasos con los que realizar las libaciones. Ahora cabe pensar que esta también sería la utilidad de grandes vasos cerámicos en forma de lebrillo que han aparecido vacíos en las inmediaciones de los pozos de acceso a los complejos funerarios. En el mismo solar del que hablamos se ha documentado uno y Juan Fernández López en el «Diario de excavación» también deja constancia de otros casos (figura 10). pozos se rellenasen tras cada enterramiento; pero obviamente no pensamos que fuese así.

Los datos sobre los que Manuel Bendala se apoya para decir que se reproduce esa práctica en Carmona son poco concluyentes. La tumba numerada por Fernández López y Bonsor como 106 (E4a305 del SICAC) no es actualmente visible, pero la descripción, que alude a una doble puerta a dos niveles distintos del pozo, resulta algo confusa. De todas formas, el relleno parece producto de un revuelto, puesto que junto a piedras hallaron restos de urnas, más que de un sellado ritual. En el caso de la tumba excavada por María Belén (número 72 del inventario de Fernández-Chicarro y Belén Deamos y F5a301 del SICAC), debe indicarse que su relleno se realizó, una vez que se había colmatado el espacio interior de la cámara, que se taponó mediante una losa (Belén Deamos 1983). Las losas que estaban a nivel superficial debían pertenecer al enterramiento de época posterior hallado bajo ellas y no al sellado del complejo funerario de la cámara.

Por otra parte, lo conocido sobre el sellado de los pozos de acceso a las cámaras hipogeas púnicas en Cartago dista de lo pretendidamente documentado en Carmona. Los pozos de acceso a tumbas individuales se sellaban con tierra, dado que nunca debían volverse a re-excavar. Pero cuando este rito se aplica a enterramientos colectivos, no se utiliza tierra, que se apelmazaría con la humedad dificultando su extracción, sino una arena fina de color blanquecino, distinta del terreno natural (Benichou-Safar 1982: 84).

Tanto en la excavación del solar frente a la Corredera como a través de las notas manuscritas de Fernández López, se documenta, con poca probabilidad de error, la colocación en las tumbas de pozo de lajas de piedra cubriendo la boca, de manera que el relleno del mismo, cuando no han sido removidas, es un barro muy fino que ha ido cayendo por las ranuras que dejan las piedras entre sí; pero tras cada enterramiento este espacio quedaba vacío y, como se ha referido, posiblemente era usado para determinados ritos relacionados con los difuntos, cuando estos no se practicaban en el exterior.

El mausoleo Cuadrangular, que es una tumba de pozo y cámara a la que se han añadido con posterioridad escaleras que no alcanzan la superficie del pozo, presenta este mismo esquema, aunque en este caso se han practicado en las losas de cerramiento superficial sendos agujeros, uno para la entrada y salida de personas y otro, más pequeño, a modo de canal de libaciones que vierte directamente sobre el pozo.

En este sentido, los complejos en los que se ha constatado la existencia de óculos en la bóveda de las 
cámaras que las comunican con el exterior deben pensarse como otras fórmulas de plasmar esos mismos ritos, sin necesidad de bajar. En todos estos casos se trata de complejos con escalera y planta más amplia que el resto de las tumbas, excepción hecha de la tumba de la Moneda de Vespasiano. Estos complejos se cerrarían, como se documentó en la mencionada tumba número 72 excavada por Belén Deamos (Belén, Gil et alii 1985), situando las lajas directamente en la puerta de la cámara. Sobre estas diferencias en los espacios para realizar la profusio, que no son las únicas documentadas en enterramientos colectivos, ya sean de carácter familiar o no, pues las libaciones en los que tenían sala con triclinio se realizaban directamente sobre unos canales especialmente dedicados a ello, apenas podemos avanzar mucho más, salvo que se carece de constatación fiable para pensar en que no sean coetáneas.

\section{SECUENCIA DE RITUALES FUNERARIOS DOCUMENTADOS EN LA NECRÓPOLIS ROMANA DE CARMONA}

Convendría, por último, ordenar secuencialmente los rituales funerarios y tipos de tumbas documentados en la necrópolis occidental de Carmona. Esta ordenación sigue la establecida por María Belén y su equipo (Belén, Gil et alii 1985), añadiendo algunos ejemplos más sobre todo de los momentos peor documentados extraídos del análisis del «Diario de excavaciones» de Juan Fernández López.

$1^{\circ}$. Inhumaciones individuales en fosa con banco lateral y cubrición de tegulae, caracterizados no solo por el ritual, sino también por presentar un ajuar compuesto dos o tres ungüentarios piriformes de cerámica (Belén, Gil et alii 1985: 53), de los que -de momento- carecemos de constancia sobre su presencia en los complejos hipogeos.

$2^{\circ}$. El conjunto de cremaciones excavadas en el entorno del anfiteatro, al menos hacia el sureste, caracterizadas por ser individuales y usar cerámicas pintadas a bandas como urnas cinerarias, así como pequeños platos a modo de tapadera. Posiblemente, el ajuar estaría compuesto por anillos y otros pequeños objetos metálicos y algún ungüentario cerámico. Inicialmente estos enterramientos se fecharon en el siglo $\mathrm{V}$ a. C. (Belén Deamos 1982), pero más tarde se rebajó la cronología a finales del siglo III o comienzos del II, por ser el momento a partir del cual aparece la decoración de retícula pintada sobre la cerámica a torno, presente en esos vasos cinerarios (Belén Deamos y Escacena Carrasco
1992: 82). Aunque en situación secundaria, la aparición de un anillo en la tumba 14 , en el interior de la urna, con un entalle en el que aparece una mosca (en opinión de María Belén, ya que Concepción Fernández-Chicarro la describió como abeja), ha obligado a bajar la cronología de este conjunto, situándola entre mediados del siglo I a. C. y mediados del siglo I d. C. (Belén Deamos y Escacena Carrasco 1994: 249 ss.), a pesar de las dudas que pesan sobre la naturaleza de esta cremación ${ }^{25}$.

Gracias a las someras notas de Juan Fernández López, en su «Diario de excavaciones», conocemos la existencia de un hallazgo realizado en 1888 , posiblemente asimilable a este tipo de enterramientos, cerca de la tumba de Postumio, del que deja anotado que se trata de un bustum rectangular y pequeño de donde se extrajo un ungüentario de barro $^{26}$.

Ambos momentos pueden haber sido coetáneos, en todo o parte, como ocurre en otras ciudades béticas, donde coexisten cremaciones e inhumaciones, sobre todo en lugares de tradición cultural fenicio-púnica, pero ya en época republicana. Caso de la necrópolis de Campos Elíseos en Gibralfaro (Málaga) (Martín y Pérez-Malumbres 1999). La presencia de ungüentarios cerámicos fusiformes y en forma de bulbo, habitual en este tipo de ambientes, apoya dataciones en los siglos II y I antes de nuestra era (Cuadrado 1977-1978; Molina Fajardo, Ruiz Hernández y Huertas Jiménez 1982 y Muñoz Vicente 1987).

$3^{\circ}$. Los complejos funerarios de pozo y cámara simple, así como sus respectivas variantes, incluidos los llamados mausoleos circulares y las tumbas de carácter colectivo, sean hipogeas, semihipogeas o meramente rehundidas en la roca. Su datación está ampliamente reconocida en el siglo I d. C., finalizando -con independencia de que muchas de ellas perduren más tiempohacia finales de esa centuria o comienzos de la siguiente (Bendala Galán 1976: 126; Fernández-Chicarro 1978; Belén Deamos 1983: 217 s.; Belén, Gil et alii 1985: 56; Mostalac Carrillo 1999).

Este es el momento de monumentalización de la necrópolis, coincidiendo con el de la ciudad (Beltrán Fortes 2001b), encontrándose presentes tipos de complejos funerarios de raigambre local en vecindad $\mathrm{y} / \mathrm{o}$ fusionados con otros de clara filiación itálica ${ }^{27}$. La aparente articulación de sectores concretos de la necrópolis

25. A. Jiménez Díez (2008: 141) califica estos enterramientos de prerromanos, dando poco crédito a las revisiones cronológicas planteadas por estos autores, pero no explica por qué.

26. ACAC III.1.3. caja 1, libro 3 [Juan Fernández López] «Diario de excavaciones $1884-1905$ » fol. $075 \mathrm{v}$.

27. Caso de los triclinios funerarios o de la tumba de Servilia. 
mediante la parcelación de los espacios y la definición de un entramado de vías funerarias, se incardina perfectamente en la tónica atestiguada en numerosas ciudades romanas del momento. De la misma manera, Carmona no es la única ciudad en que se documenta este paso de tumbas de inhumación y cremación, como las señaladas anteriormente, a las de cámara hipogea para acoger enterramientos colectivos (normalmente de cremación) ya sean familiares o no. Por ejemplo en la necrópolis del Cerrillo de los Gordos de Cástulo (Canto y Urruela 1979), en Córdoba (Vaquerizo Gil 2001), Cádiz, Baelo Claudia o Carissa Aurelia (Vaquerizo Gil 2010: passim). Los ajuares de estas tumbas coinciden con las tendencias documentadas en el resto del arco mediterráneo durante este periodo, combinando conjuntos de piezas tradicionales identificadas como romanas ${ }^{28}$, con otras procedentes de la tradición autóctona ${ }^{29}$.

$4^{\circ}$. Hacia el siglo II d. C. se observa un cambio, si bien desconocemos su magnitud y la forma en que afectó a los complejos funerarios anteriores. Se documentan cremaciones individuales en situación primaria, es decir, enterradas en el mismo lugar donde se ha producido la combustión (busta), empleando para ello fosas cerradas o recubiertas con ladrillos, tegulae, piedras o con rosca de ladrillo, del estilo de las $\mathrm{cu}$ pae (Belén, Gil et alii 1985: 56 s). Aunque este tipo se ha excavado principalmente en el sector del anfiteatro, otro conjunto importante de enterramientos análogos en forma y cronología fue localizado, junto a las cámaras hipogeas, en las fincas que constituían la antigua Necrópolis Romana de Carmona, según testimonian las anotaciones de Juan Fernández López en el «Diario de excavaciones». Conviene destacar que, en algunos casos, estos busta se han encontrado una vez amortizados los complejos funerarios del siglo I de nuestra era. Así podría interpretarse el enterramiento situado en la capa superficial del pozo de la tumba 53 de las excavadas por Fernández-Chicarro y Belén Deamos (Belén Deamos 1983), siendo la losa que lo cubría no parte del complejo funerario infrayacente, que ya tenía obturada la puerta de la cámara, sino del bustum superior. También sobre el triclinio del Olivo se excavó otro bustum, una vez que este complejo estaba cubierto de tierra.

28. Lucernas, ungüentarios de vidrio, vasos de paredes finas y otros artefactos diversos. La escasa presencia detectada de monedas, lejos de mostrar una usanza de filiación púnica, como ha sido interpretada en ocasiones, responde a su valor polisémico y variable a lo largo de todo el periodo y territorio influidos por la cultura romanoitálica (Vaquerizo Gil 2010: 41).

29. Caso de los amuletos de tradición púnica publicados por George E. Bonsor (1897).
Este momento coincide con el conocido de la necrópolis norte, en el cortinal Alto. Posiblemente también pertenezcan a él los busta excavados en el lugar conocido como «La Calderilla», situado en el entorno de la calle Sevilla ${ }^{30}$.

$$
* * * *
$$

Cabría pensar que estas nuevas evidencias e interpretaciones de las ya conocidas decantan el debate sobre punicidad o romanidad de la necrópolis occidental de Carmona más hacia esta segunda opción. Sin embargo, a pesar de la revisión a la que hemos sometido las principales tesis defendidas por Bendala sobre la filiación púnica de la necrópolis occidental de Carmona, debe afirmarse que, en efecto, hay rasgos indudablemente orientales, de progenie fenicio-púnica, que peculiarizan la necrópolis occidental de Carmona. Algo que nunca se ha puesto en cuestión y que la emparenta con otras necrópolis del ámbito andaluz ${ }^{31}$. Así lo reconoce Alföldy (2001: 382) para explicar qué entiende por romanización, en términos en el fondo similares a los usados por Bendala, excepción hecha de la vindicación étnica.

En definitiva, se trata de una cuestión cuya profundización requiere ampliar nuestro conocimiento del espacio necropolitano carmonense, mediante nuevos análisis que combinen el estudio de los vestigios descubiertos en el pasado y futuras excavaciones arqueológicas extensivas.

\section{BIBLIOGRAFÍA}

ALFÖLDY, G. (2001): "La sociedad del municipio de Carmo", A. Caballos Rufino (ed.): Carmona romana: 381-396, Sevilla.

AMORES CARREDANO, F. (2001): "Entre el campo y la ciudad. La periferia urbana de Carmo", A. Caballos Rufino (ed.): Carmona romana: 447-464, Sevilla.

AMORES CARREDANO, F.; RODRÍGUEZ-BOBADA Y GIL y SÁEZ FERNÁNDEZ, P. (2001): "La organización y explotación del territorio de Carmo", A. Caballos Rufino (ed.): Carmona romana: 413-446, Sevilla.

30. ACAC, leg. 2, lib. 7 «1893-1909. Libro de Actas de la Sociedad Arqueológica de Carmona», f. $13 \mathrm{v}$.

31. Existen abundantes trabajos sobre estas concomitancias con otras necrópolis geográficamente cercanas (Jiménez Díaz 2008 y Vaquerizo Gil 2010). 
ANGLADA CURADO, R. y COLIN HAYES, E. (2003a): "Excavaciones de urgencia en la calle de Enmedio no 19 de Carmona (Sevilla): nuevos datos sobre la necrópolis romana", Anuario Arqueológico de Andalucía 2000, vol. III-2: 1203-1217.

- (2003b): "Intervención de urgencia en el Paseo del Estatuto, Carmona (Sevilla): el mausoleo romano", Anuario Arqueológico de Andalucía 2000, vol. III2: $1218-1227$.

ASPAS JIMÉNEZ, F. y TOCINO RENTERO, G. (2004): "De morada de Bonsor a mirador excepcional de la Necrópolis de Carmona", Mus-A: Revista de los museos de Andalucía 3: 33-36.

BENDALA GALÁN, M. (1976): La necrópolis romana de Carmona (Sevilla), Sevilla.

- (1981): "La etapa final de la cultura ibero-turdetana y el impacto romanizador", La Baja Época de la Cultura Ibérica: 33-48. Madrid.

- (1982): "La perduración púnica en tiempos romanos. El caso de Carmona", Huelva Arqueológica VI: 193-203

- (1991): "El banquete funerario en el mediodía hispano: una observación”, Gerión n ${ }^{\circ}$ Extra 3: 181-186.

- (2001): "La Carmona Bárquida", A. Caballos Rufino (ed.): Carmona romana: 37-51. Sevilla.

- (2002): "Perduraciones y romanización en Hispania a la luz de la arqueología funeraria: notas para una discusión", Archivo Español de Arqueología 75: 137-158.

- (2005): "Urbanismo y romanización en el territorio andaluz: aportaciones a un debate en curso", Mainake 27: 9-32.

BELÉN DEAMOS, M. (1982): “Tumbas prerromanas de incineración en la Necrópolis de Carmona (Sevilla)", Homenaje a Conchita Fernández Chicarro, Directora del Museo Arqueológico de Sevilla: 269285, Madrid.

- (1983): "Aportaciones al conocimiento de los rituales romanos en la Necrópolis romana de Carmona", Homenaje al Prof. Martín Almagro Basch vol. III: 209-226, Madrid.

BELÉN DEAMOS, M. y ESCACENA CARRASCO, J. L. (1992): "Las comunidades prerromanas de Andalucía Occidental”, G. Ruiz Zapatero y M. Almagro-Gorbea (eds.): Paleoetnología de la Península Ibérica (Madrid 1989), Complutum 2-3: 65-88.

- (1994): "Sobre las necrópolis turdetanas", S. Ordóñez Agulla y P. Sáez Fernández (eds.): Homenaje al profesor Presedo: 237-266, Sevilla.

BELÉN DEAMOS, M.; GIL DE LOS REYES, S.; HERNÁNDEZ, G.; LINEROS ROMERO, R. y
PUYA GARCÍA DE LEANIZ, M. (1985): "Rituals funeraris a la necròpolis romana de Carmona (Sevi1la)", Cota Zero 2: 53-61.

BELÉN DEAMOS, M.; GIL DE LOS REYES, S.; LINEROS ROMERO, R. y PUYA GARCÍA DE LEANIZ, M. (1987): "Excavaciones en el campo de las Canteras (Carmona, Sevilla). El túmulo A", XVIII Congreso Nacional de Arqueología: 535548, Zaragoza.

BELÉN DEAMOS, M.; LINEROS ROMERO, R. y PUYA GARCÍA DE LEANIZ, M. (1987): "Excavaciones en la Necrópolis de Carmona (Sevilla), 1985", Anuario Arqueológico de Andalucía 1985, vol. II: 417-423.

BELTRÁN FORTES, J. (2001a): "Los devotos de Némesis en el ámbito del anfiteatro hispanoromano" Arys 4: 197-210.

- (2001b): “Arqueología de la Carmona romana: el esquema urbano", A. Caballos Rufino (ed.): Carmona romana: 135-158, Sevilla.

BENICHOU-SAFAR, H. (1982): Les tombes puniques de Carthage. Topographie, structures, inscriptions et rites funéraires, París.

BONSOR, G. E. (1897): "Notas arqueológicas de Carmona", Revista de Archivos, Bibliotecas y Museos I: 231 ss.

- (1898): "Notas arqueológicas de Carmona", Revista de Archivos, Bibliotecas y Museos II: 222-226.

- (1899a): "Notas arqueológicas de Carmona", Revista de Archivos, Bibliotecas y Museos III: 425 ss.

- (1899b): Les colonies agricoles pré-romaines de la vallée du Betis, Extrait de la Revue Archéologique XXXV ( $3^{\mathrm{a}}$ serie).

- (1931): An Archeological Sketch-book of the Roman Necropolis al Carmona, Nueva York.

BRAUNE, S. R. (2008): Convivium funebre. Gestaltung und Funktion römischer Grabtriklinien als Räume für sepulkrale Bankettfeiern, Hildesheim.

CABALLOS RUFINO, A. (2001): "La paulatina integración de Carmo en la Romanidad", A. Caballos Rufino (ed.): Carmona romana: 13-18, Sevilla.

- (2007): "Carmona romana", VV. AA. Carmona: 3661, Carmona.

CANTO, A. M. y URRUELA, J. J. (1979): "Necrópolis del «Cerrillo de los Gordos» (Campaña de 1971)", J. M. Blázquez Martínez: Castulo II, Excavaciones Arqueológicas en España 105: 321-346, Madrid.

CRUCES BLANCO, E. (dir.) (1991): Inventario del archivo y biblioteca de Jorge Bonsor, Sevilla.

CUADRADO DÍAZ, E. (1977-1978): “Ungüentarios cerámicos en el mundo ibéricoaportación 
cronológica", Archivo Español de Arqueología 5051: 389-404.

FERNÁNDEZ-CHICARRO, C. (1969): Guía del Museo y de la Necrópolis Romana de Carmona (Sevilla), Madrid.

- (1970): "Novedades en la Necrópolis romana de Carmona (Sevilla)", Bellas Artes 4: 47-52.

- (1978): "Reciente descubrimiento de una tumba romana, del siglo I de la Era en la zona del anfiteatro de Carmona", Boletín de Bellas Artes VI: 137-190.

FERNÁNDEZ LÓPEZ, J. (1887): “Memoria-Resumen de los trabajos realizados por la Sociedad Arqueológica de Carmona. Año I", Memoria de la Sociedad Arqueológica de Carmona: 20-35, Carmona.

FERNÁNDEZ LÓPEZ, M. (1886): Historia de la ciudad de Carmona, desde los tiempos más remotos hasta el reinado de Carlos I, Sevilla.

- (1899): Necrópolis romana de Carmona. Tumba del Elefante, Sevilla.

GIL DE LOS REYES, M. S. y GÓMEZ SAUCEDO, M. T. (2001): "El Conjunto Arqueológico de la Necrópolis Romana de Carmona", A. Caballos Rufino (ed.): Carmona romana: 527-540, Sevilla.

GÓMEZ DÍAZ, A. (2001): La presentación de las zonas arqueológicas en España. La Necrópolis Romana de Carmona 1881-1930, tesis de licenciatura inédita, Universidad de Sevilla.

- (2006): "El jardín arqueológico de la necrópolis romana de Carmona (Sevilla), 1881-1930. Un proyecto pionero de acondicionamiento y gestión de un yacimiento arqueológico", J.-P. Morel, J. Tresserras y J. C. Matamala (eds.): The archaeology of crop fields and gardens: 283-291, Bari.

GÓMEZ MUÑIZ, S.; FERNÁNDEZ LÓPEZ, M.; BONSOR, J. y FERNÁNDEZ LÓPEZ, J. (1887): "Inscripciones inéditas de Carmona", Boletín de la Real Academina de la Historia 10: 392-398.

HERNÁNDEZ DÍAZ, J.; SANCHO CORBACHO, A. y COLLANTES DE TERÁN, F. (1943): Carmona. Catálogo arqueológico y artístico (tirada especial del Catálogo arqueológico y artístico de la provincia de Sevilla), Sevilla.

ITINERARIO DE LA NECRÓPOLIS ROMANA DE CARMONA, Sevilla 1889.

JIMÉNEZ DÍEZ, A. (2008): Imagines Hibridae. Una aproximación postcolonialista al estudio de las necrópolis de la Bética, Madrid.

JIMÉNEZ HERNÁNDEZ, A. (2007): "La transición bronce final-Edad del Hierro en Carmona", M. Bendala Galán y M. Belén Deamos (eds.): El nacimiento de la ciudad: la Carmona protohistórica: 391-424, Sevilla.
JIMÉNEZ HERNÁNDEZ, A.; LÓPEZ SÁNCHEZ, J. M. y RODRÍGUEZ TEMIÑO, I. (2010): "Sistema de información del Conjunto Arqueológico de Carmona. Sevilla. España” VAR. Virtual Archaeological Review 1.2: 102-107. «http://www.arqueologiavirtual.com/var/num2/24.pdf»

JIMÉNEZ MARTÍN, A. (1989): La Puerta de Sevilla en Carmona, Sevilla.

MAIER ALLENDE, J. (1999): Jorge Bonsor (18551930): un Académico Correspondiente de la Real Academia de la Historia y la Arqueología Española, Madrid.

MARTÍN RUIZ, A. y PÉREZ-MALUMBRES LANDA, A. (1999): "La necrópolis de época tardo-púnica de Los Campos Elíseos (Gibralfaro, Málaga)”, Madrider Mitteilungen 40: 146-159.

MELCHOR GIL, E. (1992): "Sistemas de financiación y medios de construcción de la red viaria hispana" Habis 23: 121-138.

MOLINA FAJARDO, F.; RUIZ HERNÁNDEZ, A. y HUERTAS JIMÉNEZ, C. (1982): Almuñécar en la Antigüedad, Granada.

MORET, P. (1996): Les fortifications ibériques. De la fin de l'Âge du bronze à la conquête romaine, Madrid.

MOSTALAC CARRILLO, A. (1999): "La pintura romana en Hispania de Augusto a Nerón" Madrider Mitteilungen 40: 168-188.

MUÑOZ VICENTE, Á. (1987): “Avance sobre el estudio de los ungüentarios helenísticos de Cádiz. 1986", Anuario Arqueológico de Andalucía 1986, vol. II: 520-525.

RADA Y DELGADO, J. de D. de la (1885): Necrópolis de Carmona. Memoria escrita en virtud de acuerdo de las Reales Academias de la Historia y de Bellas Artes de San Fernando, Madrid.

RODRÍGUEZ NEILA, J. F. (1983): “Aportaciones epigráficas. I" Habis 14: 153-194.

RODRÍGUEZ TEMIÑO, I. (2010): "Repensar el concepto de conjunto arqueológico en Andalucía. A propósito del Plan Director del Conjunto Arqueológico de Carmona", V Congreso Internacional: Musealización de Yacimientos Arqueológicos. Arqueología discurso histórico y trayectorias locales: 303-316, Murcia.

RUIZ CECILIA, J. I.; RODRÍGUEZ TEMIÑO, I.; JIMÉNEZ HERNÁNDEZ, A. y GONZÁLEZ ACUÑA, D. (2011): A tumba abierta. Una nueva mirada sobre la Necrópolis Romana de Carmona a través de viejas fotografías, Sevilla.

SALES Y FERRÉ, M. (1887): Estudios arqueológicos é históricos. Necrópolis de Carmona. Funerales de 
los romanos y sus creencias acerca del alma y de la otra vida. Sarcófago visigótico de Écija. Excursión al Aljarafe, Madrid.

SCHATTNER, TH. (2005): "La Puerta de Sevilla en Carmona y otras puertas romanas en la Península Ibérica", Romula 4: 67-98.

STYLOW, A. U. (2001): "Una aportación a la Carmo romana a través de su epigrafía. Nuevas aportaciones y revisión crítica", A. Caballos Rufino (ed.): Carmona romana: 95-106, Sevilla.

THOUVENOT, R. (1940): Essai sur la province romaine de Bétique, París.
VAQUERIZO GIL, D. (2006): "Sobre la tradición púnica, o los influjos norteafricanos, en algunas manifestaciones arqueológicas del mundo funerario hispano-bético de época pleno-imperial. Una revisión crítica", D. Vaquerizo Gil y J. F. Murillo (eds.): El concepto de lo provincial en el mundo antiguo. Homenaje a la profesora Pilar León Alonso, Vol II: 317-364, Córdoba.

- (2010): Necrópolis urbanas en Baetica, Barcelona. VAQUERIZO GIL, D. y SÁNCHEZ MADRID, S. (2008): "Entre lo público y lo privado. Indicatio pedaturae en la epigrafía funeraria hispana" Archivo Español de Arqueología 